\title{
无机钲钛矿太阳能电池稳定性研究进展
}

\author{
杨英 ${ }^{a, b, c}$ 林飞宇 $a, b, c$ 朱从潭 $a, b, c$ 陈甜 ${ }^{a, b, c}$

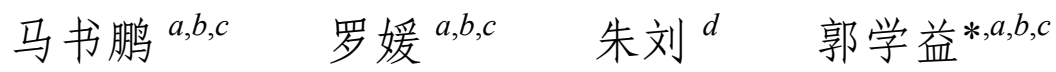 \\ $\left({ }^{a}\right.$ 中南大学 冶金与环境学院 长沙 410083) \\ ( ${ }^{b}$ 有色金属资源循环利用湖南省重点实验室 长沙 410083) \\ ( ${ }^{c}$ 有色金属资源循环利用湖南省工程研究中心 长沙 410083) \\ ( ${ }^{d}$ 广东先导稀材股份有限公司 广东 511500)
}

\begin{abstract}
摘要 近年来钲钛矿太阳能电池发展迅速, 全无机钙钛矿具有良好的热稳定性、高吸光系数、带隙可调、制备简单等 优点备受关注. 现今, 无机钻钛矿太阳能电池的最高光电转化效率已达 $19.03 \%$, 具有很好的发展潜力. 本综述将从无 机钲钛矿太阳能电池的制备方法、薄膜掺杂、界面修饰对稳定性影响入手, 系统介绍无机钲钛矿太阳能电池的发展并 进行分析总结, 并着重分析了无机钻钛矿不稳定的原因及其改善方法, 最后对于无机钙钛矿太阳能电池的未来进行了 展望.
\end{abstract}

关键词 无机钙钛矿太阳能电池; 制备方法; 界面修饰; 薄膜掺杂; 稳定性提高

\section{Research Progress in the Stability of Inorganic Perovskite Solar Cells

\begin{tabular}{|c|c|}
\hline $\begin{array}{l}\text { ing }{ }^{a, b, c} \\
\text { hupeng }^{a, b, c}\end{array}$ & $\begin{array}{l}\text { Lin, Feiyu }{ }^{a, b, c} \\
\text { Luo, Yuan }^{a, b, c}\end{array}$ \\
\hline
\end{tabular} \\ ( ${ }^{a}$ School of Metallurgy and Environment, Central South University, Changsha 410083) \\ ( ${ }^{b}$ Hunan Key Laboratory of Nonferrous Metal Resources Recycling, Changsha 410083) \\ ( ${ }^{c}$ Hunan Engineering Research Center of Nonferrous Metal Resources Recycling, Changsha 410083) \\ ( ${ }^{d}$ First Rare Materials Co., Ltd, Guangdong 511500)}

\begin{abstract}
In recent years, the efficiency of perovskite solar cells has developed rapidly, but its stability is limited by the influence of heat, light and water. All-inorganic perovskite formed by inorganic cations instead of organic cations shows improved thermal stability, high light absorption and adjustable band gap. The photoelectric conversion efficiency of all-inorganic perovskite solar cells has been improved to $19.03 \%$ at present. Among them, $\mathrm{CsPbI}_{3}$ perovskite solar cells have good photoelectric performance but poor stability, while $\mathrm{CsPBr}_{3}$ perovskite solar cells have excellent stability but poor photoelectric performance of devices. In this paper, the influence of preparation method, film doping and interface modification on the stability of inorganic perovskite solar cells is systematically summarized. The reasons behind the instability of inorganic perovskite and the improvement methods are emphatically analyzed. In conclusion, improving the stability of inorganic perovskite light absorbing materials by film doping, surface passivation and morphology control such as low dimensional materials preparation can effectively improve the stability of the overall device, which provides the basis for further commercialization. In addition, it is of great significance to study the theory of charge transfer and recombination and establish a complete theoretical system for improving the performance and stability of the device. At present, most of perovskite contains harmful elements $\mathrm{Pb}$. How to replace $\mathrm{Pb}$ and find new materials applied in perovskite solar cells is also the future development trend. In a word, as a new type of solar cell, inorganic perovskite solar cell is expected to contribute to the photovoltaic development of the future society.
\end{abstract}

Keywords inorganic perovskite solar cell; preparation method; interface modification; film doping; improved stability

\section{1 引言}

钻钛矿太阳能电池由于效率高、成本低、工艺简单 以及环境友好, 已成为了光电器件领域的研究重点 ${ }^{[1-8]}$. 2019 年, 该类太阳能电池转化效率已达到 $25.2 \%{ }^{[9]}$, 显
示了极高的发展应用潜力. 钙钛矿太阳能电池主要由光 阳极(如 $\mathrm{TiO}_{2}+\mathrm{ABX}_{3}\left(\mathrm{~A}=\mathrm{CH}_{3} \mathrm{NH}_{3}(\mathrm{MA})\right.$ 或者 $\mathrm{Cs}, \mathrm{B}=\mathrm{Pb}$, $\mathrm{X}=\mathrm{I}, \mathrm{Br}, \mathrm{Cl})$ 、钙钛矿吸光材料、空穴传输层 $(\mathrm{HTM})$ 以及 对电极组成. 其中钻钛矿吸光材料 $\mathrm{CH}_{3} \mathrm{NH}_{3} \mathrm{PbX}_{3}(\mathrm{X}=\mathrm{I}$, $\mathrm{Br}, \mathrm{Cl})$ 对光热以及水氧等极其敏感, 易分解, 使得该类

* E-mail: xyguo@csu.edu.cn; Tel.: 0731-88877863.

Received November 22, 2019; published January 13, 2020.

Project supported by the National Natural Science Foundation of China (No. 61774169), Scientific Research Foundation for the Returned overseas Chinese Scholar; Postgraduate Independent Exploration and Innovation Projects of Central South University (Nos. 2019zzts944, 502211922).

项目受国家自然科学基金(No. 61774169)、留学回国基金资助以及中南大学研究生自主探索创新项目(No. 2019zzts944, 502211922)资助. 
器件的稳定性差, 如何大幅改善钻钛矿太阳能电池稳定 性是该领域的研究难点. 为解决钙钛矿太阳能电池稳定 性问题, 国内外研究学者进行了积极的探索. 基本思路 主要分为两种: 一是提高钙钛矿材料本身的稳定性; 二 是优化电池的界面及结构. 如对钙钛矿吸光材料 $\mathrm{ABX}_{3}$ 进行基团替代、掺杂及界面修饰改性等 ${ }^{[10 \sim 17]}$. 我们组前 期研究工作将 $\mathrm{PbS}$ 量子点作为阻挡层修饰 $\mathrm{TiO}_{2}$ /钙钛矿 界面, 阻止 $\mathrm{TiO}_{2}$ 对钙钛矿的光催化分解, 达到减少电荷 复合提高器件效率的目的 ${ }^{[18]}$. 同时, 针对钙钛矿材料空 气湿度易降解的问题, 我们提出了一种新型琼脂糖/钙 钛矿复合吸光材料, 运用该复合材料制备器件, 无封装 的钙钛矿太阳能电池在空气湿度 $(\mathrm{RH}=70 \%)$ 条件下效 率为 $14.66 \%$, 并在 $1392 \mathrm{~h}$ 后保留了 $90 \%$ 的初始值 ${ }^{[19]}$, 实 现了无手套箱条件下钙钛矿太阳能电池的空气湿度稳 定.

由于优越的热稳定及光电性能, 无机钙钛矿太阳能 电池近年来越来越受关注 ${ }^{[20 ~ 23]}$. 到目前为止, 在绝大多 数无机钙钛矿材料 $\mathrm{ABX}_{3}$ 中, $\mathrm{A}$ 位置的取代物主要是 $\mathrm{Cs}$, 这是为了满足晶体容许因子在 $0.8 \sim 1.0$ 之间, 使其可以 形成稳定钙钛矿相. B 位置的取代物主要为 $\mathrm{Pb}, \mathrm{Sn}, \mathrm{Ge}$ 等. 2012 年, 基于 $\mathrm{CsSnI}_{3}$ 的无机钙钛矿太阳能电池首次 被报道, 效率为 $0.88 \%{ }^{[24]} .2014$ 年基于 $\mathrm{CsSnI}_{3}$ 的器件光 电转化效率提高到 $2.02 \%{ }^{[25 \sim 27]}$. 随后更加稳定的 $\mathrm{CsPbX}_{3}(\mathrm{X}=\mathrm{I}, \mathrm{Br}, \mathrm{Cl})$ 材料被应用到无机钙钛矿太阳能 电池中，其效率在短短时间内突破了 $10 \%{ }^{[28 ~ 30]}$. 目前多 数的无机钙钛矿还是采用 $\mathrm{Pb}$ 基钙钛矿, 其中 $\mathrm{X}$ 位的 I 原子可以被 $\mathrm{Br}$ 取代, 根据被 $\mathrm{Br}$ 取代的数目可以分为 $\mathrm{CsPbI}_{3} 、 \mathrm{CsPbI}_{2} \mathrm{Br} 、 \mathrm{CsPbIBr}_{2} 、 \mathrm{CsPbBr}_{3}$ 这 4 种类型的无 机钙钛矿吸光材料. 现今报道的最高的无机钙钛矿太阳 能电池是基于 $\beta-\mathrm{CsPbI}_{3}$ 吸光材料体系, 采用苯基三甲基 氯化铵 $(\mathrm{PTACl})$ 钝化钙钛矿表面, 器件的光电转化效率 达到 $19.03 \%{ }^{[31]}$. 有研究表明 $\mathrm{CsPbI}_{3}$ 及 $\mathrm{CsPbBr}_{3}$ 可以在接 近其熔点的 $460{ }^{\circ} \mathrm{C}$ 保持稳定的结构与组成 ${ }^{[32]}$.

尽管无机钙钛矿太阳能电池具有很好的热稳定性. 但其依然存在以下的问题需进一步解决 ${ }^{[33]}$ : (1)进一步开 发有效的制备方法以控制无机钙钛矿材料的结晶、生长 以及形貌; (2)无机钻钛矿太阳能电池依然存在化学不稳 定性, 易于晶相转变; (3)新的器件结构的设计及理解, 优化空穴传输层及电子传输层界面是进一步提高无机 钲钛矿太阳能电池光电转化效率的关键. 在 $\mathrm{CsPbI}_{3}$ 、 $\mathrm{CsPbI}_{2} \mathrm{Br} 、 \mathrm{CsPbIr}_{2} 、 \mathrm{CsPbBr}_{3}$ 这 4 种无机钙钛矿吸光材 料中, 卤族元素的比例不仅可以决定光吸收特性及结构 稳定性, 还可以促进器件的光伏特性. $\mathrm{CsPbI}_{3}$ 具有最适 宜的带隙但稳定性较差, $\mathrm{CsPbBr}_{3}$ 的稳定性较好但带隙 较宽. 近年来关于无机钙钛矿太阳能电池的光电效率改 善的报道很多, 但在稳定性方面的综述报道相对较少. 总体来说, 无机钙钛矿太阳能电池的晶相稳定性依然是 现在该方向的难点以及瓶颈之一. 本文根据不同无机钙
钛矿薄膜的特点，总结了不同薄膜制备方法的优缺点以 及改善器件光电性能的方法，同时依据材料的不同着重 分析总结了 $\mathrm{CsPbI}_{3} 、 \mathrm{CsPbI}_{2} \mathrm{Br} 、 \mathrm{CsPbIBr}_{2} 、 \mathrm{CsPbBr}_{3}$ 这 4 种无机钙钛矿薄膜及器件稳定性机制及稳定性改善的 策略, 并对无机钙钛矿太阳能电池的未来发展做出了展 望.

\section{2 无机钙钛矿太阳能电池结构及工作原理} 计算 ${ }^{[34]}$ :

$$
t=\left(r_{\mathrm{A}}+r_{\mathrm{X}}\right) /\left(2^{1 / 2}\left[r_{\mathrm{B}}+r_{\mathrm{X}}\right]\right)
$$

其中, $r_{\mathrm{A}}, r_{\mathrm{B}}, r_{\mathrm{X}}$ 分别为 $\mathrm{A}, \mathrm{B}, \mathrm{X}$ 的原子半径, $t$ 的大小 决定了晶体的结构. 当 $0.8<t<1.0$ 时, 可以形成钙钛矿 型的晶体. 但当 $t<0.9$ 时, 由于 $\mathrm{BX}_{6}$ 八面体的倾斜, 钙 钛矿晶体结构会发生畸变, 使得晶体结构不稳定.

无机钻钛矿会由于环境湿度的不同而产生四种晶 体结构: 立方结构的 $\alpha$ 相、四方晶体结构的 $\beta$ 相、正斜 方结构的 $\gamma$ 相以及正交结构的 $\delta$ 相. 其中 $\delta$ 相为非钙钛 矿结构. 随着研究的深入, 目前还出现了一些钻钛矿型 衍生物的晶体结构, 而且大都在无机非铅钙钛矿中, 如 $\mathrm{A}_{2} \mathrm{BX}_{6} 、 \mathrm{~A}_{2} \mathrm{~B}_{1}+\mathrm{B}_{3}+\mathrm{X}_{6} 、 \mathrm{~A}_{3} \mathrm{~B}_{2} \mathrm{X}_{9}$ (图 1a). 无机钙钛矿太阳 能电池的工作原理为: (1)当太阳光照射到钙钛矿层时, 钙钛矿层吸收光子产生激子, 发生电子和空穴的分离; (2)分离的电子跃迁到电子传输层的导带进行传输至光 阳极, 空穴通过空穴传输层的价带传输至对电极 [过程 (1)和(2)]; (3)电子和空穴分别由相应的电极进行收集后 在外电路产生电流. 此过程中还会发生一些不利反应, 如激子湮没，导致光致发光 [过程(3)]或非辐射复合 [过 程(4)], 以及载流子在三个界面 [过程(5)至(7)] 的复合, 与光生电荷的提取相互竞争. 这些过程都是影响器件性 能的不利因素(图 1b).

\section{3 无机钙钛矿薄膜的制备方法}

无机钲钛矿 $\left[\mathrm{ABX}_{3}(\mathrm{~A}=\mathrm{Cs}, \mathrm{B}=\mathrm{Pb}, \mathrm{X}=\mathrm{F}, \mathrm{Cl}, \mathrm{Br})\right.$ ]薄 膜常用的制备方法为溶液法. 一般是根据钙钛矿的类型 不同, 主要是 $\mathrm{I}$ 与 $\mathrm{Br}$ 的比例不同, 将 $\mathrm{CsI} 、 \mathrm{CsBr} 、 \mathrm{PbI}_{2}$ 、 $\mathrm{PbBr}_{2}$ 按照一定物质的量比例等溶解在 $N, N$-二甲基甲酰 胺(DMF)或二甲基亚砜(DMSO) 中 ${ }^{[37]}$. 制成前驱体溶液, 再进行旋涂退火. $\mathrm{CsPbI}_{3}$ 无机钙钛矿一般是采用一步旋 涂法进行制备, 由于 $\mathrm{PbBr}_{2}$ 和 $\mathrm{CsBr}$ 的溶解度较低, 所以 在制备含有 $\mathrm{Br}$ 元素的无机钙钛矿时会采用两步旋涂法 进行制备. 用常规的溶液旋涂法所制备的薄膜存在膜面 不连续, 覆盖率不高以及晶体增长难以控制的缺点. 针 对常规无机钙钛矿薄膜制备方法存在的问题, 研究者们 提出了改进的薄膜制备方法, 以下将详细介绍几种辅助 旋涂法优化薄膜制备的方法，同时将介绍新的物理化学 沉积法: 蒸镀法以及热沉积法. 


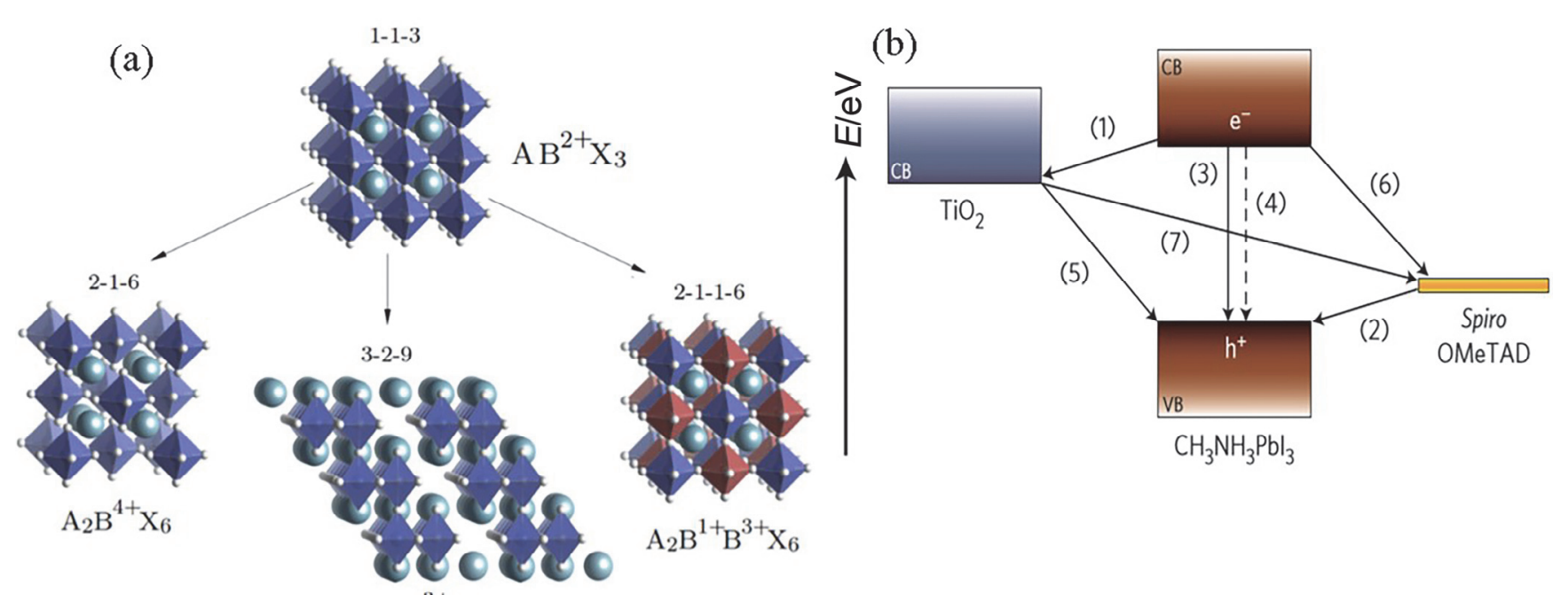

$\mathrm{A}_{3} \mathrm{~B}_{2}^{3+} \mathrm{X}_{9}$

图 1 (a)无机钙钣矿的一些典型结构图 ${ }^{[35]}$; (b)无机钙钛矿太阳能电池的基本原理示意图 ${ }^{[36]}$

Figure 1 (a) Representative crystal structures of inorganic perovskite ${ }^{[33]}$; (b) basic principle diagram of perovskite solar cells ${ }^{[36]}$

\section{1 一步旋涂法优化}

一步旋涂法是最常见的制备方法, 操作简单, 但过 程可变因素多, 重复性低. 常规的一步旋涂法很难控制 结晶过程, 通常会使制得的薄膜产生大量针孔, 严重影 响器件的性能. 目前最常用的优化方法就是反溶剂法. 通过在旋涂时滴加氯苯、异丙醇、乙酸乙酯等较难溶解 钙铁矿的物质, 与溶剂结合在退火过程中加快晶体的生 长, 提高薄膜质量. 研究者们在反溶剂法的基础上, 通 过其他方法继续优化旋涂过程, 力求获得致密平整的钙 铁矿薄膜. 经研究表明, 二甲基亚砜(DMSO)可以促进 溶剂的传质和扩散, 降低溶剂的蒸发速率可以改善钙钛 矿层膜的质量. Wang 等 ${ }^{[38]}$ 采用了溶剂控制生长法(图 2a), 将刚旋涂好的 $\mathrm{CsPbI}_{3}$ 钻钛矿薄膜在手套箱中放置 一段时间后再加热退火. 在无空气的条件下制成的器件 的光电转换效率(PCE) 达到了 $15.71 \%$. Yin 等 ${ }^{[39]}$ 分别将 $\mathrm{PbI}_{2}$ 和 $\mathrm{PbBr}_{2}$ 溶解在 $\mathrm{DMSO}$ 中, 并以氯苯作为反溶剂, 在真空中加热蒸发, 制得 DMSO 的加合物粉末 $\mathrm{PbI}_{2}$ (DMSO)和 $\mathrm{PbBr}_{2}$ (DMSO), 再将加合物粉末制成前驱液 进行旋涂, 最后得到了具有低缺陷态密度的大颗粒 $\mathrm{CsPbI}_{2} \mathrm{Br}$ 薄膜(图 $2 \mathrm{~b}$ ), 其载流子寿命长, 稳定性高, 由 于粒径大, 光生载流子可以自由传输, 不会被晶界上存 在的缺陷所阻断. 使得开路电压和填充因子分别为 1.22 $\mathrm{V}$ 和 $78.7 \%$, 光电转换效率达到了 $14.78 \%$. Chen 等 ${ }^{\left[{ }^{[0]}\right]}$ 采 用梯度退火的方法制备 $\mathrm{CsPbI}_{2} \mathrm{Br}$ 薄膜, 梯度退火可以有 效控制钙针矿的结晶过程, 使其形成致密的大尺寸晶粒 以降低缺陷密度, 同时采用异丙醇(IPA)作为绿色反溶 剂, 制得的钲钛矿晶体平均粒径为 $1 \mu \mathrm{m}$, 光电效率为 $16.07 \%$ 的无机钻钛矿太阳能电池. 常规一步旋涂方法 制备的 $\mathrm{CsPbI}_{2} \mathrm{Br}$ 薄膜, 其退火温度一般需在 $300{ }^{\circ} \mathrm{C}$ 下 进行, Wang 等 ${ }^{[41]}$ 采用热沉积低温法制备了 $\mathrm{CsPbI}_{2} \mathrm{Br}$ 薄 膜, 先将基底加热至 $55{ }^{\circ} \mathrm{C}$, 之后再进行旋涂, 并且退 火温度只需要 $120{ }^{\circ} \mathrm{C}$ (图 2c), 制成器件的效率达到了
$12.5 \%$. 这种低温法的退火温度低, 制备过程更加简单 安全.

\section{2 两步旋涂法优化}

常规两步旋涂法常用来制备 $\mathrm{CsPb}\left(\mathrm{I}_{1}-{ }_{x} \mathrm{Br}_{x}\right)_{3}$ 薄膜, 由 于 $\mathrm{PbBr}_{2}$ 以及 $\mathrm{CsBr}$ 在溶液中的溶解度很低, 采用两步法 可以提高薄膜的成膜质量, 但器件效率却很低. Tang 等 ${ }^{[42]}$ 采用多步法制备 $\mathrm{CsPbBr}_{3}$ 薄膜, 并详细研究了多步 法制备的形成机理. 在旋涂一层 $\mathrm{PbBr}_{2}$ 后, 分别旋涂 1 至 6 次 $\mathrm{CsBr}$. 并发现在旋涂小于 3 次时, 会形成 $\mathrm{CsPb}_{2} \mathrm{Br}_{5}$ 衍生物, 而大于 5 次时又会形成 $\mathrm{Cs}_{4} \mathrm{PbBr}_{6}$ 衍生 物, 只有在旋涂 4 次后会形成 $\mathrm{CsPBr}_{3}$, 且均匀致密, 粒 径大小理想. 组成器件的光电转换效率最高达到了 $9.72 \% . \mathrm{Yu}$ 等 ${ }^{[43]}$ 在 $\mathrm{CsBr}$ 的甲醇溶液中加入一定体积的 DMSO, 通过两步法工艺, 获得了具有高表面平整度、 表面覆盖度、结晶性和大晶粒尺寸的 $\mathrm{CsPb}\left(\mathrm{I}_{1-x} \mathrm{Br}_{x}\right)_{3}$ 无机 钻钛矿薄膜. 制得器件的光电效率为 $13.27 \%$. 目前对于 溶液两步旋涂法的优化研究还很少, 需要进一步寻找合 适的方法制备性能优良的钙钛矿薄膜.

\section{3 其他新方法}

为了克服 $\mathrm{PbBr}_{2}$ 溶解度很低的问题, $\mathrm{Ho}$ 等 ${ }^{[44]}$ 采用了 顺序喷雾沉积法, 将 CsI 喷涂到 $\mathrm{PbBr}_{2}$ 薄膜上, 形成 $\mathrm{CsPbIBr}$, 制成的器件光电转换效率为 $6.3 \%$. $\mathrm{Ma}$ 等 ${ }^{[45]}$ 采用双源共蒸发法制备了 $\mathrm{CsPbIBr}_{2}$, 将 $\mathrm{CsI}$ 与 $\mathrm{PbBr}_{2}$ 粉 末同时加热沉积, 控制一定蒸发速率保持二者物质的量 比为 $1: 1$, 并做成了无空穴传输层的器件, 器件光电转 化效率为 $4.7 \%$. Lei 等 ${ }^{[46]}$ 同样采用双源真空蒸渡法制备 $\mathrm{CsPbBr}_{3}$ (图 2d), 器件光电转化效率为 $6.95 \%$. 这种真空 蒸发的方法虽然操作复杂, 但可以制备大粒径致密的优 质薄膜, 有效地改善了器件的光电效率.

旋涂反溶剂法是最常见的制备方法，其操作简单, 可获得高质量的钙铁矿薄膜, 但制备过程中的影响因素 
(a)

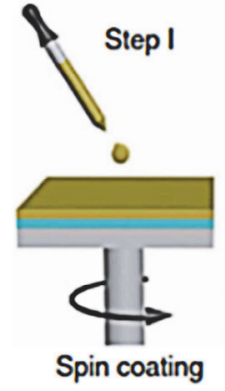

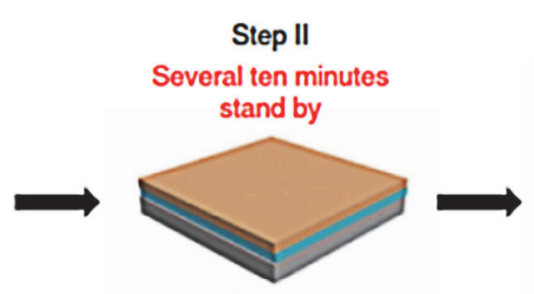

Solvent-controlled growth (SCG)

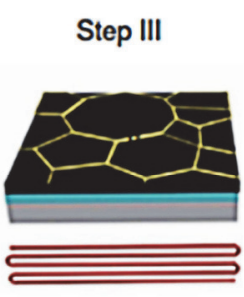

Annealing (b) wDISO-adducts (c)

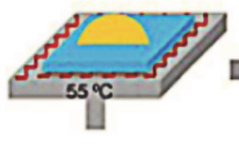

Hot-cast

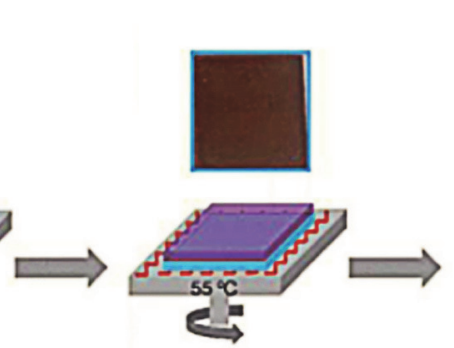

$\mathrm{CsPbl}_{2} \mathrm{Br}$ precursor film

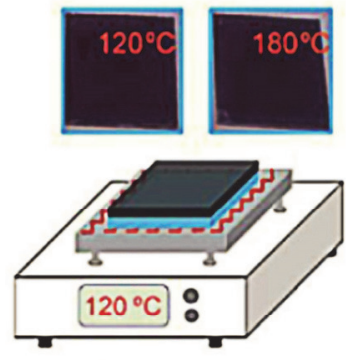

Post-annealing

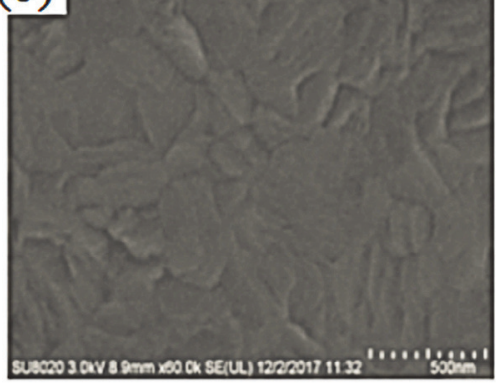

(d)

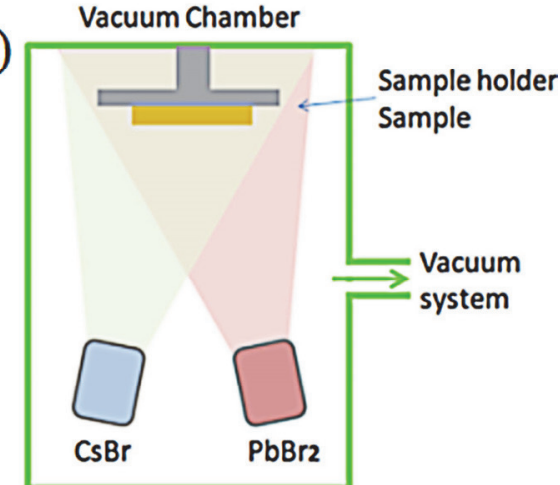

图 2 (a)溶剂控制生长法制备 $\mathrm{CsPb}_{3}$ 示意图 ${ }^{[38]}$; (b)用 DMSO 加合物制备的 $\mathrm{CsPbI}_{2} \mathrm{Br}$ 薄膜 $\mathrm{SEM}$ 图 ${ }^{\left[{ }^{[39]}\right.}$; (c) $\mathrm{CsPb}_{2} \mathrm{Br}$ 热沉积制备过程图 ${ }^{[41]}$; (d)真空双 源共沉积制备 $\mathrm{CsPbBr}_{3}$ 薄膜示意图 ${ }^{[46]}$

Figure 2 (a) Preparation of $\mathrm{CsPbI}_{3}$ by solvent controlled growth ${ }^{[38]}$; (b) SEM surface images of $\mathrm{CsPbI}_{2} \mathrm{Br}$ films with DMSO-adducts ${ }^{[39]}$; (c) process chart of $\mathrm{CsPbI}_{2} \mathrm{Br}$ thermal deposition ${ }^{[41]}$; (d) schematic diagram of $\mathrm{CsPbBr}_{3}$ films prepared by vacuum dual source co-deposition ${ }^{[46]}$

颇多, 使得实验结果的重复性差. 在接下来的研究中, 应控制其成膜过程，通过一些添加剂或者新的制备方 法, 如喷雾沉积等, 控制生长结晶动力学, 提高实验的 重复性, 或找到适用于无机钙铁矿制备的新方法, 这对 于未来商业化的发展起着重要的作用.

\section{4 无机钙钛矿太阳能电池光电性能优化}

\section{1 薄膜掺杂}

元素掺杂可有效改善无机钻铁矿薄膜的表面缺陷、 晶格稳定以及电荷输运能力. 对分子结构为 $\mathrm{ABX}_{3}$ 的无 机钙铁矿, 其元素掺杂分为两种: $\mathrm{A}$ 位原子以及 $\mathrm{B}$ 位原 子掺杂取代. 对 $\mathrm{A}$ 位原子的掺杂研究, 鲜有报道, $\mathrm{A}$ 原子 主要是 $\mathrm{Cs}$ 原子; $\mathrm{B}$ 位原子掺杂取代的研究主要集中在 $\mathrm{Pb}$ 的同族元素掺杂, 稀土元素掺杂以及其他元素掺杂. 同 时, 由于 $\mathrm{CsPbI}_{3}$ 极易晶相转变, 对于 $\mathrm{CsPb}_{3}$ 的元素掺杂 大都为改善其晶相稳定性; $\mathrm{CsPbBr}_{3}$ 掺杂的目的主要在 于调控其能带结构增加吸光能力或改善其晶格缺陷以 提高光电转化效率.

\subsubsection{A 位原子掺杂取代}

$\mathrm{Jae}$ 等 ${ }^{[47]}$ 使用 $\mathrm{K}$ 元素掺杂, 使少量 $\mathrm{Cs}$ 原子被 $\mathrm{K}$ 原 子取代, 形成了 $\mathrm{Cs}_{0.925} \mathrm{~K}_{0.075} \mathrm{PbI}_{2} \mathrm{Br}$ 钙钛矿, $\mathrm{K}$ 的掺入一方 面促进了光激发载体的形成和运输, 提高了器件的电流 密度 $\left(J_{\mathrm{sc}}\right)$, 使器件的光电效率最高达到了 $10.0 \%$; 另一 方面, 使 $\mathrm{PbX}_{6}$ 八面体体积收缩, 提高了相稳定性. Guo
等 ${ }^{[48]}$ 将 $\mathrm{Rb}$ 掺杂到 $\mathrm{CsPbI}_{2} \mathrm{Br}$ 中, 形成了 $\mathrm{Cs}_{0.99} \mathrm{Rb}_{0.01} \mathrm{PbI}_{2} \mathrm{Br}$ 这种类型的钙铁矿. $\mathrm{Rb}$ 的加入使钙钛矿薄膜具有良好的 结晶性且表面无针孔, 通过稳态光致发光光谱可以看出 $\mathrm{Rb}$ 加入减小了电子的复合率(图 3a), 最终制得器件的光 电转化效率达到了 $12 \%$.

由于晶体结构的原因, 对 $\mathrm{A}$ 位原子进行掺杂取代的 原子不能进入晶体内部，只会与表面的原子进行取代， 这就导致了对 $\mathrm{A}$ 位原子取代比较困难且掺杂原子较少, 很难从本质上改变钻钣矿的性质. 对于 $\mathrm{A}$ 位原子的取代 还需要进一步研究, 寻找有利其掺杂取代的新方法.

\subsection{2 $\mathrm{B}$ 位 $\mathrm{Pb}$ 同族元素掺杂}

Liang 等 ${ }^{[49]}$ 采用了 $\mathrm{Sn}$ 掺杂的方法, 制备了 $\mathrm{CsPb}_{0.9^{-}}$ $\mathrm{Sn}_{0.1} \mathrm{IBr}_{2}$ 这种类型的钙铁矿薄膜, $\mathrm{Sn}$ 的掺杂拓宽了其吸 光范围, 经测量其禁带宽度为 $1.79 \mathrm{eV}$, 很接近 $\mathrm{CsPbI}_{3}$ 的 禁带宽度. 使用碳做对电极并代替空穴传输层, 器件的 开路电压达到了 $1.26 \mathrm{~V}$, 光电转化效率为 $11.30 \%$. Yang 等 ${ }^{[50]}$ 探究了 $\mathrm{Ge}$ 掺杂对 $\mathrm{CsPb}_{1-x} \mathrm{Ge}_{x} \mathrm{I}_{2} \mathrm{Br}$ 的影响, 发现当 $x=0.3$ 时形成的 $\mathrm{CsPb}_{0.7} \mathrm{Ge}_{0.3} \mathrm{I}_{2} \mathrm{Br}$ 组成器件的开路电压达 到了 $1.34 \mathrm{~V}$ (图 3b), 是当时无机钙铁矿材料中最高的开 路电压. 通过 $\mathrm{Ge}$ 的掺杂有效优化晶格的性质, 增强了 对太阳光的吸收能力, 而且器件的稳定性也有所提高.

\subsubsection{B 位稀土元素掺杂}

Duan 等 ${ }^{[51]}$ 探究了镧系元素掺杂对 $\mathrm{CsPbBr}_{3}$ 钙铁矿 的影响, 发现在钙钛矿晶格中加入镧系离子后, 晶粒尺 
寸增大, 载流子寿命延长. 器件的效率都有所提高(图 $3 \mathrm{c}$ ), 其中使用 $\mathrm{Sm}^{3+}$ 掺杂的器件效率最高, 为 $10.14 \%$ 并 且开路电压高达 $1.594 \mathrm{~V}$. Xiang 等 ${ }^{[52]}$ 同样使用稀土元素 $\mathrm{Eu}$ 掺杂到 $\mathrm{CsPbI}_{2} \mathrm{Br}$ 中, 制成 $\mathrm{CsPb}_{0.95} \mathrm{Eu}_{0.05} \mathrm{I}_{2} \mathrm{Br}$ 钙钛矿, $\mathrm{Eu}$ 的掺杂使晶粒变小, 形成致密无针孔的钲钛矿薄膜. 光致发光光谱(PL)发生略微蓝移, 可能是 $\mathrm{Eu}$ 的加入改 变了钙钛矿的能带结构. 最终制成器件的光电效率为 $13.34 \%$. 可以看出稀土元素的加入可以改善钻钛矿薄 膜的形貌和光电性能, 有效提高器件的效率.

\subsubsection{B 位其他元素掺杂}

$\mathrm{Lau}$ 等 ${ }^{[53]}$ 探究了不同浓度 $\mathrm{Ca}$ 元素掺杂对 $\mathrm{CsPbI}_{3}$ 钻 钛矿的影响, 发现 $\mathrm{Ca}$ 的加入会产生多重影响. 首先, $\mathrm{Ca}^{2+}$ 的存在降低了前驱液中胶体的尺寸，使成核反应物 和薄膜结晶反应物的分布更加均匀, 从而导致更大的晶 粒和更光滑的薄膜, 使得钲钛矿界面与空穴传输层界面 可以更好地接触, 增加了器件的开路电压 $\left(V_{\mathrm{oc}}\right)$ 和填充因
子(FF); 其次, $\mathrm{Ca}$ 在钙钛矿表面形成富钙氧化物层, 钝 化部分表面，延迟载流子寿命; 最后, $\mathrm{Ca}$ 的加入改变了 钙钛矿的能级结构, 使禁带宽度变大. 制成器件的光电 效率最高为 $13.5 \%$. Zhang 等 ${ }^{[54]}$ 采用低温法将 $\mathrm{Sr}$ 掺入 $\mathrm{CsPbI}_{2} \mathrm{Br}$ 中, 形成 $\mathrm{CsPb}_{0.98} \mathrm{Sr}_{0.02} \mathrm{I}_{2} \mathrm{Br}$. 其器件的光电效率 从未掺杂的 $6.6 \%$ 提高到了 $11.3 \%$ (图 3d). 这是由于 $\mathrm{Sr}$ 在钙钛矿表面富集, 产生了钝化效果, 提高了有效电荷 的寿命，使得开路电压与填充因子都有所提高.

对 $\mathrm{B}$ 位原子的掺杂取代是目前最常见, 也是研究最 多的. 进行取代的原子选择种类也很多，不同的原子所 带来的晶体性质变化不同，带来的影响也不同．例如一 些半径小于 $\mathrm{Pb}^{2+}$ 的原子进行掺杂后可以有效提高钙钛 矿晶体的稳定性，一些过渡元素金属可以控制结晶过程 得到大粒径晶体, 而稀土元素目前看来对器件的性能提 升最为有利. 在今后的研究中, 应注重机理方面的探究, 深入了解取代原子的行为及其对晶体性质的改变.

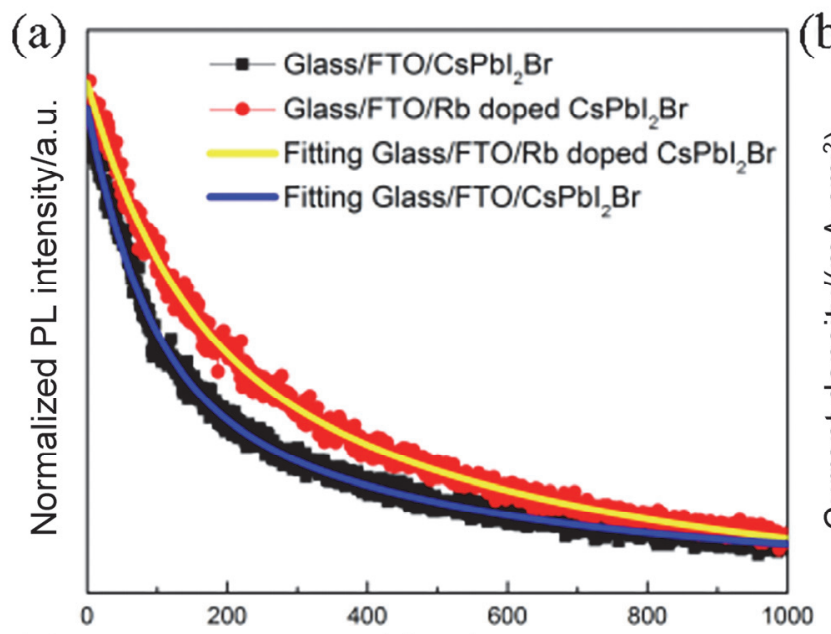

(c)
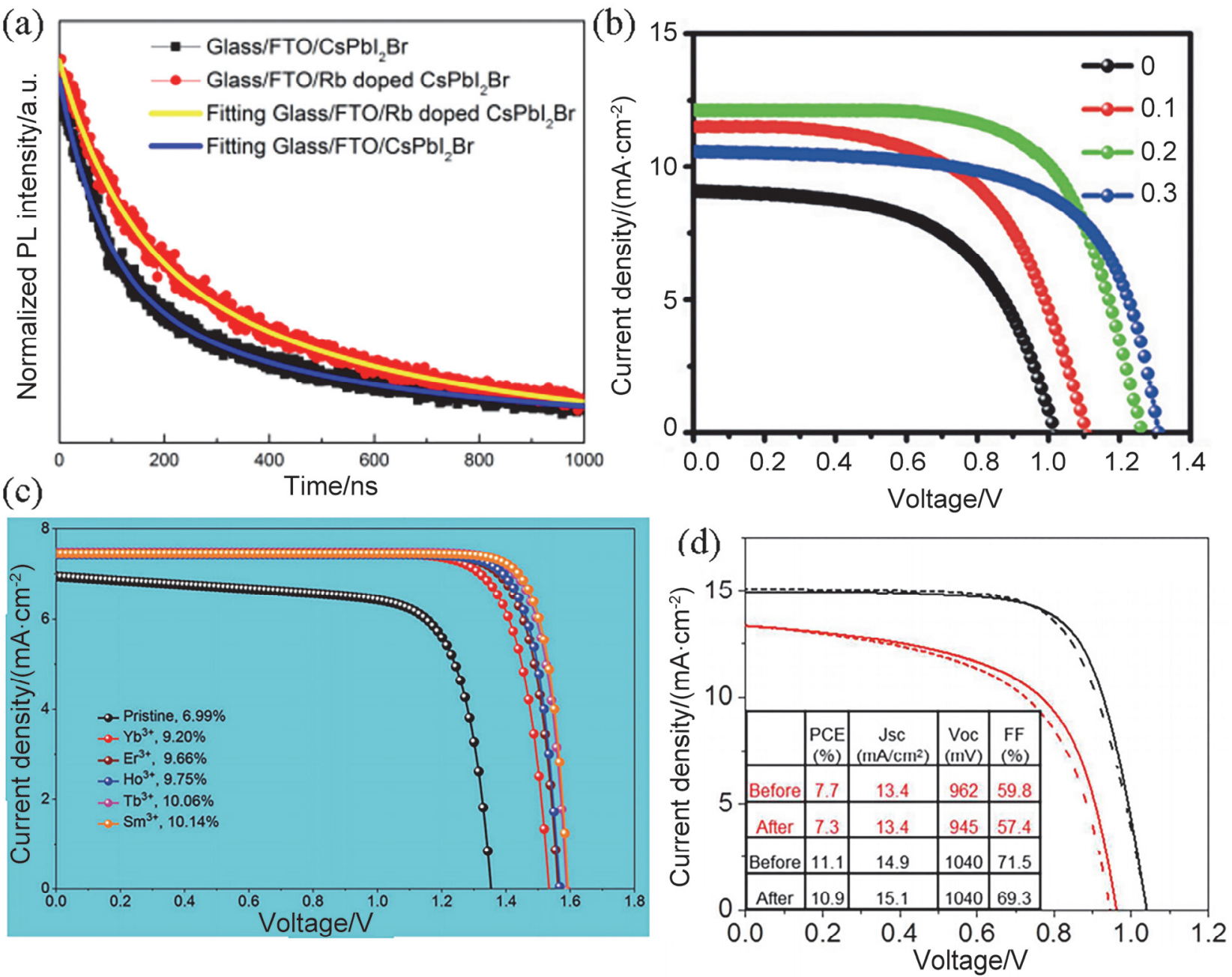

图 3 (a) $\mathrm{CsPbI}_{2} \mathrm{Br}$ 和 $\mathrm{Cs}_{0.99} \mathrm{Rb}_{0.01} \mathrm{PbI}_{2} \mathrm{Br}$ 薄膜的稳态光致发光图 ${ }^{[48]}$; (b) $\mathrm{CsPb}_{1-x} \mathrm{Ge}_{x} \mathrm{I}_{2} \mathrm{Br}$ 组成器件的 $J-V$ 曲线图 ${ }^{[50]}$; (c) 不同稀土元素掺杂的 $\mathrm{CsPbBr}$ 组成器件的 $J-V$ 曲线图 ${ }^{[51]}$; (d) $\mathrm{CsPb}_{0.98} \mathrm{Sr}_{0.02} \mathrm{I}_{2} \mathrm{Br}$ 和 $\mathrm{CsPb}_{2} \mathrm{Br}$ 组成器件的 $J-V$ 曲线图 ${ }^{[54]}$

Figure 3 (a) TRPL spectral of $\mathrm{CsPbI}_{2} \mathrm{Br}$ and $\mathrm{Cs}_{0.99} \mathrm{Rb}_{0.01} \mathrm{PbI}_{2} \mathrm{Br}_{\text {film }}{ }^{[48]}$; (b) $J-V$ curve of the $\mathrm{CsPb}_{1-x} \mathrm{Ge}_{x} \mathrm{I}_{2} \mathrm{Br} \mathrm{PSCs}^{[50]}$; (c) $J-V$ curves of CSPbBr $3 \mathrm{PSCs}$ doped with different rare earth elements ${ }^{[51]}$; (d) $J-V$ curve of $\mathrm{CsPb}_{0.98} \mathrm{Sr}_{0.02} \mathrm{I}_{2} \mathrm{Br}$ and $\mathrm{CsPbI}_{2} \mathrm{Br} \mathrm{PSCs}^{[54]}$ 


\section{2 界面修饰}

界面修饰是优化无机钙钛矿太阳能界面电荷传输 的常见方法, 能有效地改善电荷的注入途径, 减少电荷 复合, 以提高器件的光电转化效率. 现有研究中, 对无 机钙钛矿太阳能电池的界面修饰, 从修饰目的来讲, 可 分为减少电荷复合的界面修饰以及优化器件吸光能力 的界面修饰。

\subsection{1 减少电荷复合}

量子点具有可调带隙和高吸收系数等优点, 是一种 很有潜力的界面修饰材料, $\mathrm{Li}$ 等 ${ }^{[55]}$ 首次将 $\mathrm{PbS}$ 量子点引 入杂化钙钛矿中, 在当时获得了 $8 \%$ 的光电效率以及近 $100 \mathrm{~h}$ 的稳定性. 在我们前期研究中曾多次使用量子点 作为一种修饰材料 ${ }^{[66 ~ 59]}$. Yuan 等 ${ }^{[60]}$ 使用碳量子点 (CQDs) 和磷量子点 (PQDs) 分别修饰 $\mathrm{TiO}_{2} / \mathrm{CsPbBr}_{3}$ 与 $\mathrm{CsPbr}_{3} /$ carbon 界面. 通过界面能级匹配以促进电子与 空穴的分离(图 4b)光伏效率从 $6.05 \%$ 提高到了 $7.93 \%$. Yuan 等 ${ }^{[61]}$ 制备了结构为: $\mathrm{ITO} / \mathrm{SnO}_{2} / \mathrm{ZnO} / \mathrm{CsPbI}_{2} \mathrm{Br} / \mathrm{Spiro}-$ $\mathrm{OMeTAD} / \mathrm{MoO}_{3} / \mathrm{Ag}$ 这种以 $\mathrm{SnO}_{2}$ 和 $\mathrm{ZnO}$ 为双层电子传 输层的器件, $\mathrm{ZnO}$ 的能级为 $-4.21 \mathrm{eV}$, 在 $\mathrm{SnO}_{2}(-4.43$ $\mathrm{eV}$ )与 $\mathrm{CsPbI}_{2} \mathrm{Br}(-4.16 \mathrm{eV})$ 之间(图 4a), 这样可以提供 一个理想的能级差, 来减少电子复合并加强对电子的提 取. 界面修饰后的器件开路电压和填充因子明显提高,
$V_{\mathrm{oc}}$ 达到 $1.23 \mathrm{~V}, \mathrm{FF}$ 为 $78.8 \%$, 光电转换效率为 $14.6 \%$.

\section{2 .2 优化器件吸光能力及电荷传输}

由于 $\mathrm{CsPbBr}_{3}$ 的禁带宽度为 $2.3 \mathrm{eV}$, 导致其只能吸 收波长小于 $550 \mathrm{~nm}$ 的太阳光 ${ }^{[62]}$, 这限制了其器件的光 电性能. Yuan 等 ${ }^{[63]}$ 为了增强其吸光能力, 使用有机吸光 层 $\mathrm{SnS}: \mathrm{ZnS}$ 与 $\mathrm{CsPbBr}_{3}$ 共同制备成混合吸光层(图 4c), 使其吸光能力拓宽到 $700 \mathrm{~nm}, J_{\mathrm{sc}}$ 增加到 $8.21 \mathrm{~mA} / \mathrm{cm}^{2}$, 最终实现了 $10.26 \%$ 的光电转化效率, 为 $\mathrm{CsPbBr}_{3}$ 基无机 钙钛矿太阳能电池至今报道的最高效率. Wang 等 ${ }^{[64]}$ 在 $\mathrm{CsPbI}_{3}$ 薄膜上旋涂了一层三甲基苯基溴化铵 (PTABr) (图 4d), 其器件结构为 $\mathrm{FTO} / \mathrm{TiO}_{2} / \mathrm{PTABr}-\mathrm{CsPbI}_{3} / \mathrm{Spiro}$ $\mathrm{MeOTAD} / \mathrm{Ag}$ ，由于 $\mathrm{PTA}$ 基团的疏水性以及 $\mathrm{Br}$ 在 $\mathrm{CsPbI}_{3}$ 薄膜内成垂直浓度梯度分布, 同时实现了 $\mathrm{CsPbI}_{3}$ 薄膜掺 杂与表面针化, 使得该器件 $V_{\mathrm{oc}}=1.104 \mathrm{~V}, J_{\mathrm{sc}}=18.76$ $\mathrm{mA} / \mathrm{cm}^{2}, F F=80.6 \%$, 光电转化效率为 $17.06 \%$. 最近, Zhao 等 ${ }^{[31]}$ 采用三甲基苯基氯化铵 $(\mathrm{PTACl})$ 来针化 $\beta-\mathrm{CsPb}_{3}$ 钲钛矿的表面, 与 $\mathrm{PTABr}$ 不同, $\mathrm{Br}^{-}$会在整个钻 钛矿的晶格中扩散, 而 $\mathrm{PTACl}$ 处理后的 $\mathrm{CsPbI}_{3}$ 中的 $\mathrm{Cl}^{-}$ 仅集中在钙铁矿的表面，这些表面掺杂的 $\mathrm{Cl}^{-}$不仅钝化 了薄膜表面缺陷同时也提高了薄膜稳定性. 最终获得了 $19.03 \%$ 的光电转换效率.

(a)

(b)

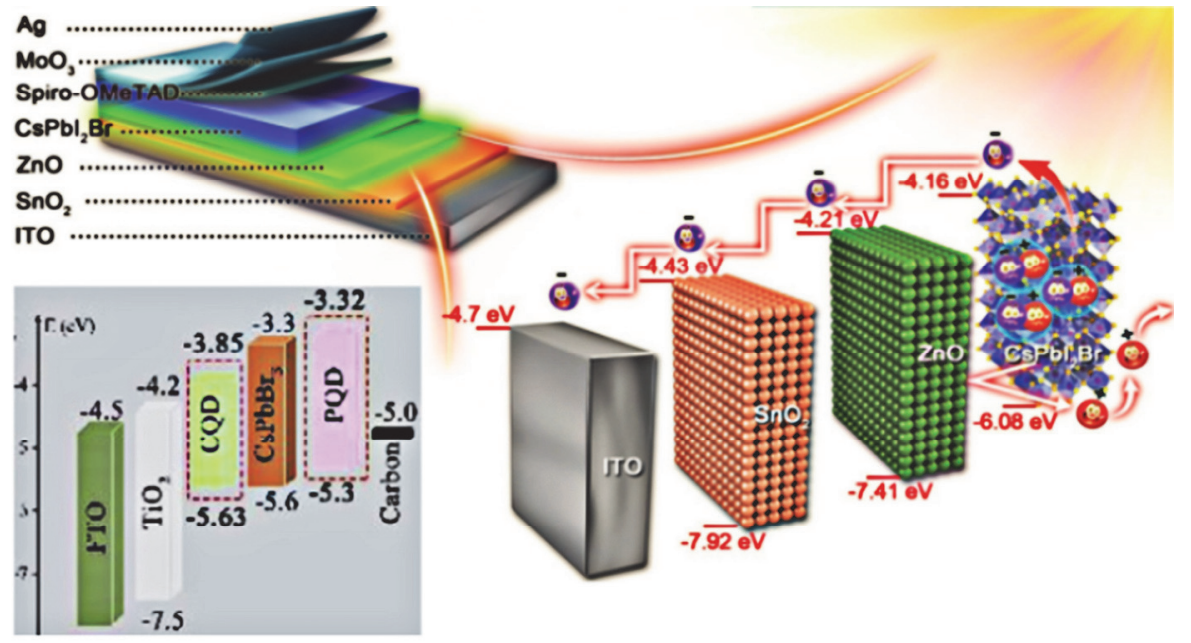

(c)

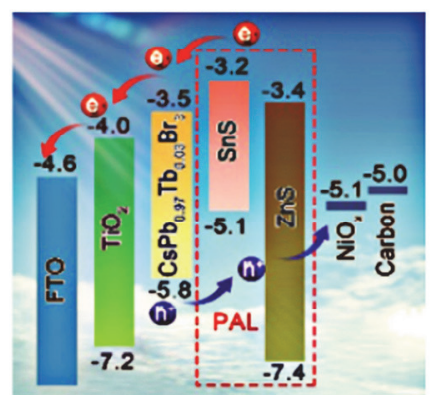

(d)

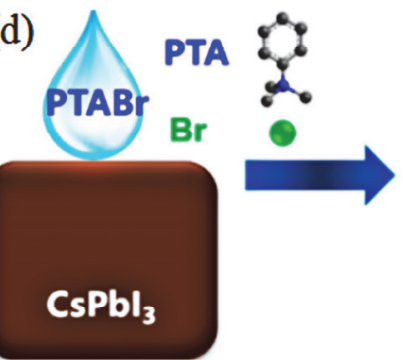

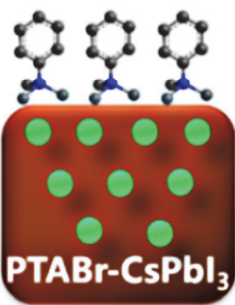

图 4 (a) $\mathrm{CsPbI}_{2} \mathrm{Br}$ 组成 PSCs 的结构及其能级示意图 ${ }^{[61]}$; (b) $\mathrm{CsPbBr}_{3}$ 组成 PSCs 能级示意图 ${ }^{[62]}$; (c) $\mathrm{CsPb}_{0.97} \mathrm{~Tb}_{0.03} \mathrm{Br}_{3}$ 组成 PSCs 能级以及电荷转移过 程示意图 ${ }^{[63]}$; (d) $\mathrm{CsPbI}_{3}$ 上梯度 $\mathrm{Br}$-掺杂和 $\mathrm{PTA}$ 有机阳离子表面针化的示意图 ${ }^{[64]}$

Figure 4 (a) Device architecture of the all-inorganic $\mathrm{CsPbI}_{2} \mathrm{Br}$ PSCs and the corresponding energy diagrams ${ }^{[61]}$; (b) schematic diagram of $\mathrm{CsPbBr}{ }_{3} \mathrm{PSCs}$ energy level ${ }^{[62]}$; (c) energy level diagram of the $\mathrm{CsPb}_{0.97} \mathrm{~Tb}_{0.03} \mathrm{Br}_{3}$ and charge-transfer processes ${ }^{[63]}$; (d) schematic illustration of gradient $\mathrm{Br}$ doping and $\mathrm{PTA}$ organic cation surface passivation on $\mathrm{CsPb}_{3}$ perovskite thin film ${ }^{[64]}$ 
限制无机钙钛矿太阳能电池效率的一个主要原因 就是界面之间的非辐射复合导致器件的能量损失严重, 使得开路电压降低. Shen 等 ${ }^{[65]}$ 通过掺杂经典碱金属碳酸 盐 $\mathrm{Cs}_{2} \mathrm{CO}_{3}$ 来调节溶胶一凝胶法制备的氧化锌电子传输材 料(ETM) 的能级和电学性质. $\mathrm{Cs}_{2} \mathrm{CO}_{3}$ 掺杂的氧化锌与 $\mathrm{CsPbI}_{2} \mathrm{Br}$ 钙钛矿层接触时具有更好的界面能, 可以将欧 姆损耗降低到可以忽略的程度. 优化后的器件开路电压 达到了 $1.28 \mathrm{~V}$, 光电转换效率为 $16.42 \%$.

通过对界面修饰, 优化器件结构及电荷输运, 从而 增强对电子的提取, 减小电子与空穴的复合, 是有效提 高无机钙钛矿太阳能电池光电转化效率的重要方法. 表 1 列出了上述不同的界面修饰方法下制备不同类型的无 机钙钛矿所组成器件的结构.

\section{5 无机钙钛矿太阳能电池稳定性优化}

\section{1 温度对无机钲钛矿稳定性的影响}

有机无机杂化钙钛矿对温度很敏感, 这是有机离子 的存在导致的, 最常见的 $\mathrm{MAPbI}_{3}$ 由于甲胺离子 $\left(\mathrm{MA}^{+}\right)$ 是酸性质子, 在光照及高温条件下, 超氧化物和甲胺部 分之间反应, 使钙钛矿中分解出 $\mathrm{PbI}_{2} 、 \mathrm{~Pb} 、 \mathrm{I}_{2}$ 从而使材 料失效 ${ }^{[67]}$. 无机钙钛矿对温度及光照的稳定性有很大
提高, 其中的 $\mathrm{Pb}$ 与 $\mathrm{I}$ 也不会分解析出. 但由于晶体热力 学性质的原因, 无机钻钛矿晶体在不同温度下会呈现出 不同的晶体结构. $\mathrm{CsPbI}_{3}$ 钻钛矿在不同温度下的晶体结 构如图 5 所示: 在 $360{ }^{\circ} \mathrm{C}$ 时为黑色的 $\alpha$ 相, 在 $260{ }^{\circ} \mathrm{C}$ 时 为黑色的 $\beta$ 相, 在 $175{ }^{\circ} \mathrm{C}$ 时为黑色的 $\gamma$ 相, $25{ }^{\circ} \mathrm{C}$ 时为黄 色的 $\delta$ 相 ${ }^{[68]}$. 将温度加热至 $300{ }^{\circ} \mathrm{C}$ 以上时又会回到黑色 的 $\alpha$ 相. 其中 $\delta$ 相为非钙钛矿相, 不能用作吸光材料. 采 用 $\mathrm{Br}$ 取代 I 可以增加晶体容许因子, 从而降低其在 $\alpha$ 相 所需的温度, 如 $\mathrm{CsPbBr}_{3}$ 在 $130{ }^{\circ} \mathrm{C}$ 时为 $\alpha$ 相 ${ }^{[95]}$. 可以看 出, 温度对无机钻钛矿的晶体类型有着很大的影响, 因 此，在一般制备过程中的退火温度要比有机一无机杂化 钻钛矿的高.

\section{2 湿度对无机钙钛矿稳定性的影响}

影响无机钙钛矿晶体稳定性的另一因素就是水, Al-Jassim 等 ${ }^{[69]}$ 通过阴极发光光谱研究表明, 无机钙钛 矿 $\alpha$ 相向 $\delta$ 相的转变开始于晶界处, 晶界处的结构缺陷 会与周围的水分子相互作用从而引发相变, 并从晶界开 始往晶体内部扩散, 最终使整个钲钛矿薄膜发生相变 (图 6). 这使得大部分无机钻钛矿难以在湿度空气中稳 定存在, 并且对无机钙钛矿的制备过程氛围要求很严 格. $\mathrm{CsPbBr}_{3}$ 无机钙钛矿放置在 $40 \% \mathrm{RH}$ 和 $25{ }^{\circ} \mathrm{C}$ 下 $3 \mathrm{~h}$

表 1 不同优化方法制备无机钲铁矿的器件结构及效率

Table 1 Device structure and efficiency of inorganic perovskite prepared by different optimization methods

\begin{tabular}{|c|c|c|c|c|}
\hline Method & Device structure & $\eta / \%$ & Remarks & Ref. \\
\hline \multirow[t]{9}{*}{ 制备方法 } & $\mathrm{ITO} / \mathrm{SnO}_{2} / \mathrm{CsPbI}_{3} / \mathrm{Spiro}-\mathrm{MeOTAD} / \mathrm{Au}$ & 15.70 & 一步旋涂 & {$[38]$} \\
\hline & $\mathrm{FTO} / \mathrm{TiO}_{2} / \mathrm{CsPbI}_{2} \mathrm{Br} / \mathrm{PCBM} / \mathrm{Ag}$ & 14.78 & 一步旋涂 & [39] \\
\hline & $\mathrm{ITO} / c-\mathrm{TiO}_{2} / \mathrm{CsPbI}_{2} \mathrm{Br} / \mathrm{Spiro}-\mathrm{MeOTAD} / \mathrm{Au}$ & 16.07 & 一步旋涂 & {$[40]$} \\
\hline & $\mathrm{FTO} / c-\mathrm{TiO}_{2} / m-\mathrm{TiO}_{2} / \mathrm{GQDs} / \mathrm{CsPbBr} /$ Carbon & 9.72 & 多步旋涂 & [41] \\
\hline & $\mathrm{FTO} / \mathrm{TiO}_{2} / \mathrm{CsPb}\left(\mathrm{I}_{1-x} \mathrm{Br}_{x}\right)_{3} /$ Spiro-MeOTAD/Au & 13.27 & 有机溶剂添加 & [42] \\
\hline & $\mathrm{ITO} / \mathrm{SnO}_{2} / \mathrm{CsPbI}_{2} \mathrm{Br} / \mathrm{PTAA} / \mathrm{MoO}_{3} / \mathrm{Al}$ & 12.50 & 低温热沉积 & [43] \\
\hline & $\mathrm{FTO} / c-\mathrm{TiO}_{2} / m-\mathrm{TiO}_{2} / \mathrm{CsPbIBr} / 2$ Spiro-MeOTAD/Au & 6.30 & 顺序喷雾沉积 & [44] \\
\hline & $\mathrm{FTO} / m-\mathrm{TiO}_{2} / \mathrm{CsPbIBr} / \mathrm{Au}$ & 4.70 & 双源共蒸发 & {$[45]$} \\
\hline & $\mathrm{FTO} / c-\mathrm{TiO}_{2} / \mathrm{CsPbBr}_{3} / \mathrm{Spiro-MeOTAD} / \mathrm{Au}$ & 6.95 & 双源共蒸发 & {$[46]$} \\
\hline \multirow[t]{8}{*}{ 元素掺杂 } & $\mathrm{FTO} / \mathrm{TiO}_{2} / \mathrm{Cs}_{0.925} \mathrm{~K}_{0.075} \mathrm{PbI}_{2} \mathrm{Br} /$ Spiro-MeOTAD/Au & 10.00 & 减少缺陷 & [47] \\
\hline & $\mathrm{FTO} / \mathrm{Nb}_{2} \mathrm{O}_{5} / \mathrm{Cs}_{0.99} \mathrm{Rb}_{0.01} \mathrm{PbI}_{2} \mathrm{Br} /$ Carbon & 12.00 & 减少缺陷 & [48] \\
\hline & $\mathrm{FTO} / m-\mathrm{TiO}_{2} / \mathrm{CsPb}_{0.9} \mathrm{Sn}_{0.1} \mathrm{IBr}_{2} /$ Carbon & 11.30 & 改善晶格 & [49] \\
\hline & $\mathrm{FTO} / \mathrm{SnO}_{2} / \mathrm{CsPb}_{0.7} \mathrm{Ge}_{0.3} \mathrm{I}_{2} \mathrm{Br} / \mathrm{P} 3 \mathrm{HT} /$ Spiro-MeOTAD/Au & 9.00 & 改善晶格 & {$[50]$} \\
\hline & $\mathrm{FTO} / c-\mathrm{TiO}_{2} / m-\mathrm{TiO}_{2} / \mathrm{CsPb}_{0.97} \mathrm{Sm}_{0.03} \mathrm{Br}_{3} /$ Carbon & 10.14 & 改善晶格 & [51] \\
\hline & $\mathrm{FTO} / c-\mathrm{TiO}_{2} / m-\mathrm{TiO}_{2} / \mathrm{CsPb}_{0.95} \mathrm{Eu}_{0.05} \mathrm{I}_{2} \mathrm{Br} / \mathrm{Spiro}-\mathrm{MeOTAD} / \mathrm{Au}$ & 13.71 & 改善晶格 & [52] \\
\hline & $\mathrm{FTO} / c-\mathrm{TiO}_{2} / m-\mathrm{TiO}_{2} / \mathrm{CsPb}_{1-x} \mathrm{Ca}_{x} \mathrm{I}_{3} / / \mathrm{P} 3 \mathrm{HT} / \mathrm{Au}$ & 13.50 & 多重效益 & {$[53]$} \\
\hline & $\mathrm{FTO} / c-\mathrm{TiO}_{2} / \mathrm{CsPb}_{0.98} \mathrm{Sr}_{0.02} \mathrm{I}_{2} \mathrm{Br} / \mathrm{P} 3 \mathrm{HT} / \mathrm{Au}$ & 11.20 & 减少缺陷 & [54] \\
\hline \multirow[t]{6}{*}{ 界面修饰 } & $\mathrm{FTO} / c-\mathrm{TiO}_{2} / m-\mathrm{TiO}_{2} / \mathrm{CQDs} / \mathrm{CsPbBr}_{3} / \mathrm{PQDs} /$ Carbon & 7.93 & 能级匹配 & {$[60]$} \\
\hline & ITO $/ \mathrm{SnO}_{2} / \mathrm{ZnO} / \mathrm{CsPbI}_{2} \mathrm{Br} /$ Spiro-OMeTAD/ $\mathrm{MoO}_{3} / \mathrm{Ag}$ & 14.60 & 能级匹配 & [61] \\
\hline & $\mathrm{FTO} / c-\mathrm{TiO}_{2} / m-\mathrm{TiO}_{2} / \mathrm{CsPb}_{0.97} \mathrm{~Tb}_{0.03} \mathrm{Br}_{3} / \mathrm{SnS}: \mathrm{ZnS} / \mathrm{NiO}_{x} /$ Carbon & 10.26 & 拓宽吸光 & {$[63]$} \\
\hline & $\mathrm{ITO} / \mathrm{Cs}_{2} \mathrm{CO}_{3}-\mathrm{ZnO} / \mathrm{CsPbI}_{2} \mathrm{Br} / \mathrm{PCBM} / \mathrm{Ag}$ & 16.42 & 能级匹配 & [65] \\
\hline & $\mathrm{FTO} / \mathrm{TiO}_{2} / \mathrm{PTABr}-\mathrm{CsPbI} /$ Spiro-MeOTAD/Ag & 17.06 & 表面包覆 & {$[64]$} \\
\hline & $\mathrm{FTO} / \mathrm{TiO}_{2} / \mathrm{CsPbI}_{2} \mathrm{Br} / \mathrm{FA} * \mathrm{CsPbX}_{3} / \mathrm{FA}^{*} \mathrm{QDs} / \mathrm{Au}$ & 14.81 & 能级匹配 & {$[66]$} \\
\hline
\end{tabular}


钙铁矿相对稳定, 颜色无明显变化, 但 $\mathrm{CsPbIBr}_{2}$ 、 $\mathrm{CsPbI}_{2} \mathrm{Br}$ 和 $\mathrm{CsPbI}_{3}$ 通过水分侵蚀呈现快速相变 ${ }^{[70]}$. 因 此, 如何在湿度空气中保持无机钻钛矿的相稳定性是限 制其发展的主要原因之一. 在效率有了一定突破的基础 上, 提高无机䥻钛矿薄膜及其器件的稳定性, 尤其是晶 相稳定性极为重要. 下面将从不同无机钻钛矿材料角度 来分析无机钙钛矿太阳能电池稳定性的改善方法.

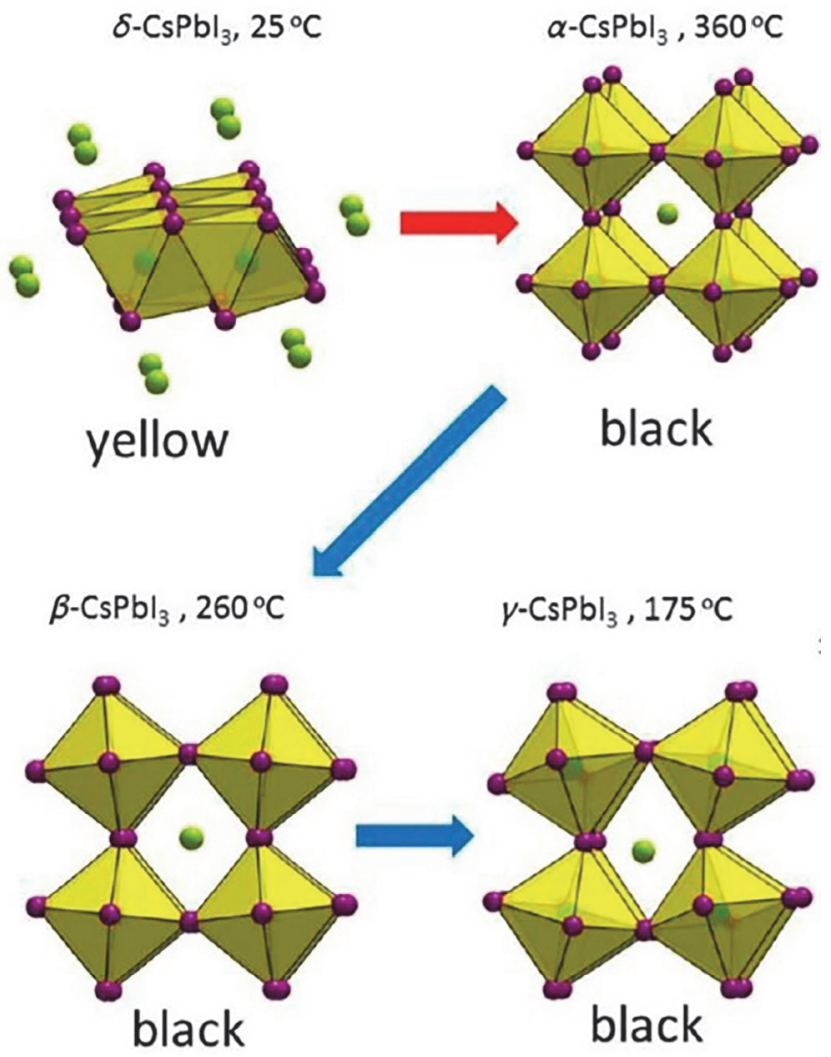

图 $5 \mathrm{CsPbI}_{3}$ 钻钣矿晶体不同温度下的晶体类型 ${ }^{[68]}$

Figure 5 Crystal types of $\mathrm{CsPbI}_{3}$ perovskite at different temperatures ${ }^{[68]}$

\section{$5.3 \mathrm{CsPbl}_{3}$ 钙钛矿薄膜及器件稳定性改善方法}

$\mathrm{CsPbI}_{3}$ 钙铁矿的禁带宽度为 $1.73 \mathrm{eV}$, 是含 $\mathrm{Pb}$ 无机 钻钣矿吸光材料中最佳的禁带宽度 ${ }^{[71]}$, 器件的极限电 流密度约为 $22 \mathrm{~mA} / \mathrm{cm}^{2}$. 但由于 Cs 原子半径较小, 使得 $\mathrm{CsPbI}_{3}$ 钙钛矿晶体结构不稳定, 其晶体的容许因子为 0.807 , 在室温下晶体结构具有热力学不稳定的性质, 正 八面体会发生倾斜, 很容易由黑色的 $\alpha-\mathrm{CsPbI}_{3}$ 相经过三 步相转变为黄色的 $\delta-\mathrm{CsPbI}_{3}$ 相 ${ }^{[72]}$, 而 $\delta$ 相为非钙铁矿结 构, 会导致器件失效, 加热至 $300{ }^{\circ} \mathrm{C}$ 以上时, 又会回到 黑色的 $\alpha$ 相. Eperon 等 ${ }^{[73]}$ 在 $300{ }^{\circ} \mathrm{C}$ 以上的氮气环境中, 首次合成出黑色 $\alpha-\mathrm{CsPbI}_{3}$ 相, 且器件光电转换效率为 $2.9 \%$ (图 7a), 但稳定性极差. 因此, 如何阻止钻铁矿晶 体由黑色相变为黄色相是当前研究的重点. 目前, 稳定 $\mathrm{CsPbI}_{3}$ 晶相的方法主要有三种: (1) 将 $\mathrm{CsPbI}_{3}$ 制成低维材 料; (2)添加剂改性; (3)元素掺杂.
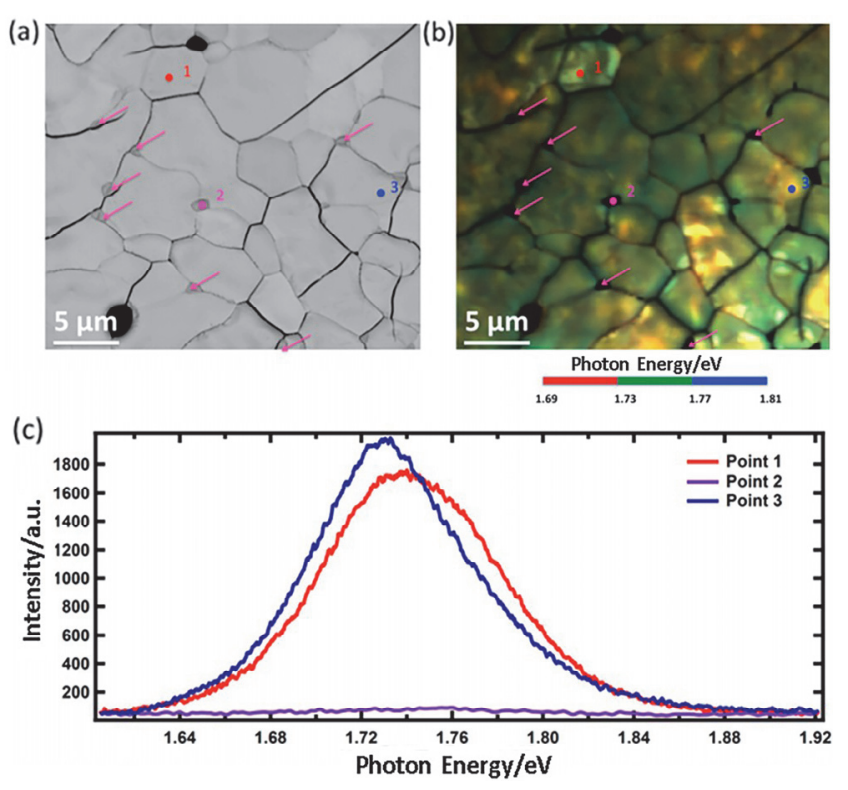

图 $6 \mathrm{CsPbI}_{3}$ 钙铁矿薄膜的(a)扫描电镜图; (b) 阴极发光光谱图像; (c) (a)中 $1 、 2$ 和 3 点的阴极发光光谱 ${ }^{[69]}$

Figure 6 (a) SEM image; (b) CL image of $\mathrm{CsPbl}_{3}$ perovskite film; (c) CL spectra of points 1,2 and 3 in (a) $)^{[69]}$

\subsection{1 $\mathrm{CsPbI}_{3}$ 低维材料的研究}

将 $\mathrm{CsPb}_{3}$ 制备成低维材料, 主要是量子点(零维材 料)和二维材料后，相稳定性有明显的提高. 由于量子 点的三维尺寸都小于 $10 \mathrm{~nm}$, 具有很高的表面能, 可以 使晶体稳定，不会轻易发生相变，因此将 $\alpha-\mathrm{CsPb}_{3}$ 制成 量子点可以使其稳定存在. Luther 等 ${ }^{[74]}$ 将 $\mathrm{CsPb}_{3}$ 制备成 量子点, 所制备的无机钙钛矿太阳能电池的光电效率为 $10.77 \%$, 在干燥的环境下放置 $60 \mathrm{~d}$ 依然稳定(图 7b). 之 后他们通过甲缕碘( $\mathrm{FAI}$ )量子点修饰 $\mathrm{CsPbI}_{3}$ 量子点, 将 器件光电效率提高到了 $13.43 \%{ }^{[75]}$. 最近, Liu 等 ${ }^{[76]}$ 使用 微波石墨交联 $\mathrm{CsPbI}_{3}$ 量子点, 使其具有更好的稳定性. 在手套箱中放置 1 个月其效率几乎没有衰减, 并且在 $100{ }^{\circ} \mathrm{C}, 60 \%$ 的湿度下也表现出不错的稳定性.

层状 $2 \mathrm{D}_{-}-\mathrm{CsPb}_{3}$ 薄膜是由一个八面体层构成的, 八 面体层通过二维连接，在三维空间中被一个有机阳离子 隔开. 由于有机阳离子的作用, 阻挡水分子进入钙钛矿 晶体中, 可以有效提高其稳定性 ${ }^{[77]}$. 但与普通的三维漹 钛矿相比, 二维材料的介电常数低导致激子结合能大, 通过添加少量 $\mathrm{A}$ 位原子形成 $2 \mathrm{D} / 3 \mathrm{D}$ 混合钙钣矿可以有 效提高其性能.

\subsection{2 添加剂改性 $\mathrm{CsPbI}_{3}$}

在钙铁矿前驱液中加入某些添加剂从而提高器件 的性能与稳定性是常见的优化方法. 在前驱液中加入添 加剂控制 $\mathrm{CsPb}_{3}$ 结晶过程, 获得较小的晶粒稳定晶相. 研究者发现在前驱液中加入适量的 $\mathrm{HI}$, 可使得 $\mathrm{CsPbI}_{3}$ 产生晶格畸变致使相转变温度降低, $\mathrm{CsPbI}_{3}$ 退火温度可 降低为 $100{ }^{\circ} \mathrm{C}$, 并维持晶相稳定. Luo 等 ${ }^{[78]}$ 除了在前驱 
液中加入 $\mathrm{HI}$, 还将制得的 $\mathrm{CsPbI}_{3}$ 浸泡在异丙醇中(IPA), 形成了一种 $\mathrm{Cs}_{4} \mathrm{PbI}_{6}$ 中间相, 再由 $\mathrm{Cs}_{4} \mathrm{PbI}_{6}$ 向 $\alpha-\mathrm{CsPb}_{3}$ 转 变, 使其在相对湿度低于 $30 \%$ 的空气中稳定存在 $72 \mathrm{~h}$. Wang 等 ${ }^{[79]}$ 用碘化胆碱(CHI)处理钙钛矿表面, 减轻了钙 钛矿层中裂纹和针孔的影响, 增加了电荷载流子寿命, 改善了 $\beta-\mathrm{CsPbI}_{3}$ 吸收层和载流子选择性接触之间的能级 匹配问题(图 7c). 结果表明, 在 $(45 \pm 5){ }^{\circ} \mathrm{C}$ 的环境条件 下, 器件的光电转化效率达到了 $18.4 \%$. 器件在手套箱 中持续光照 $500 \mathrm{~h}$ 工作后仍能保持原有效率的 $90 \%$ 以上, 具有很好的稳定性.

最近, 研究者们发现长链铵添加剂对钙钛矿材料的 结构和稳定性有很大的影响 ${ }^{[80]}$. 这些长链铵离子作为
表面配位基，可以抑制 $\mathrm{CsPbI}_{3}$ 晶粒的生长和聚集，以此 来稳定 $\alpha-\mathrm{CsPbI}_{3}$ 相. Huang 等 ${ }^{[81]}$ 在前驱液中加入磺基甜 菜碱型两性离子, 发现这种离子通过与溶液中的离子和 胶体的静电作用, 可以减缓钙钛矿薄膜的结晶过程, 得 到了晶粒在 $30 \mathrm{~nm}$ 左右的钙钛矿晶体, 形成致密的无机 钙钛矿薄膜, 对水分有较好的稳定性, 制得的器件在空 气中可维持 $30 \mathrm{~d}$ 的稳定性. Liu 等 ${ }^{[82]}$ 在前驱液中加入了 长链铵一一苯乙基碘化铵(PEAI), 发现 PEAI 为优化结 晶提供了成核作用，更重要的是它能通过空间位阻效应 阻止晶体发生相转变(图 7d). 制成的器件在空气中放置 2 个月后效率为最初的 $92 \%$.
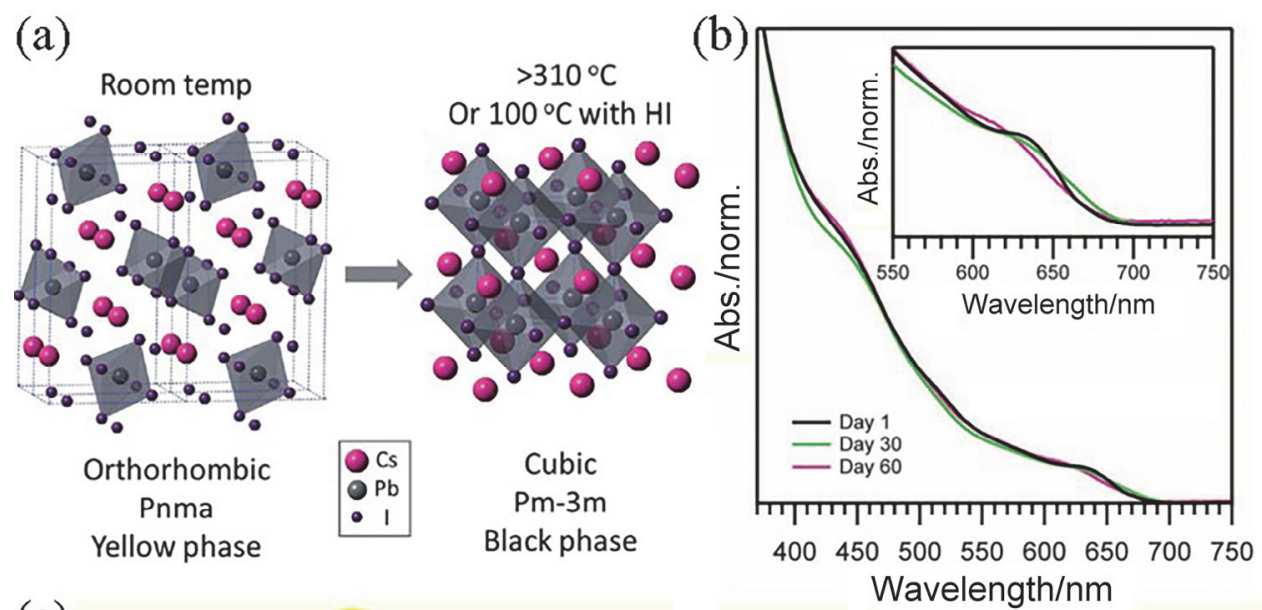

(c)
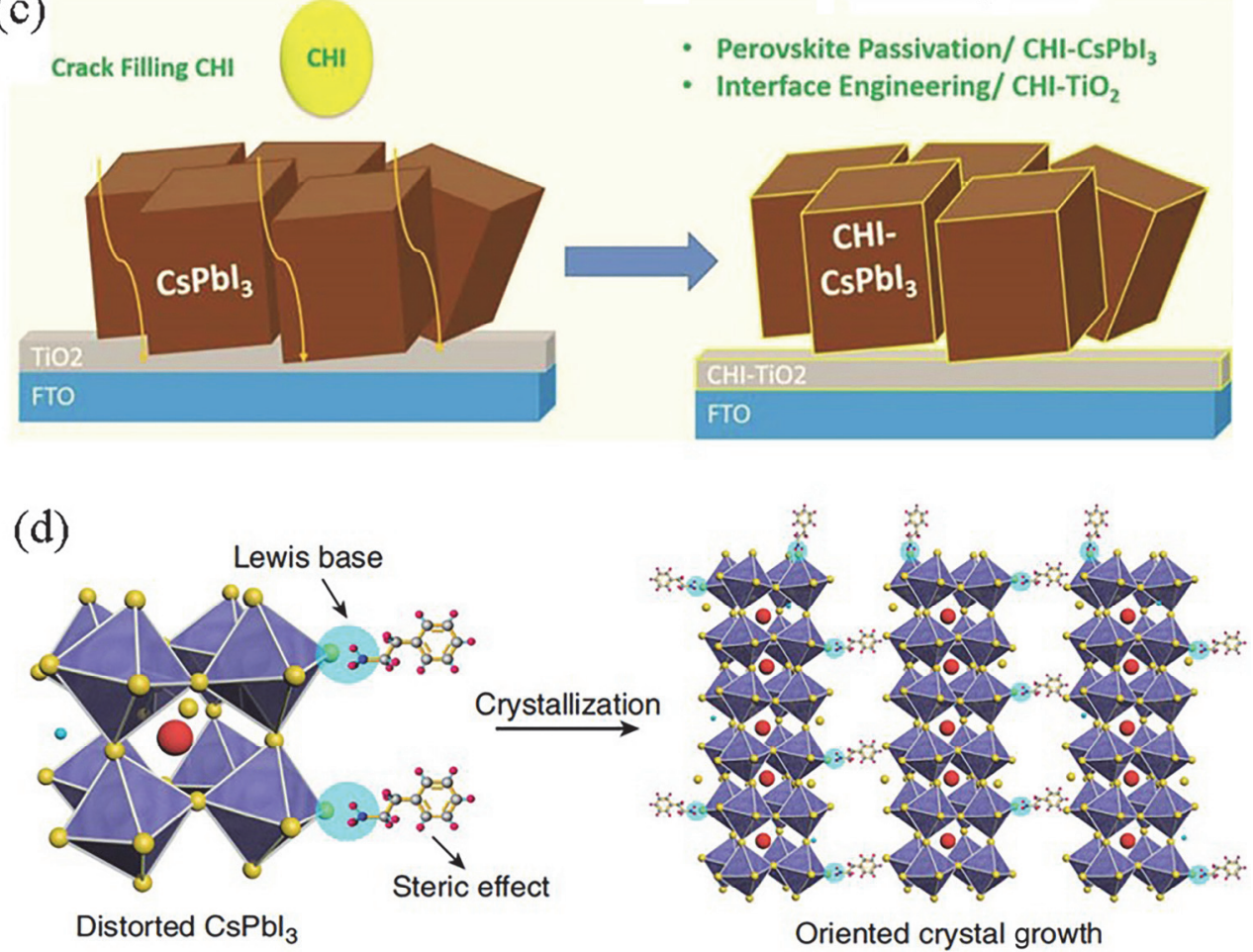

图 7 (a) $\alpha-\mathrm{CsPbI}_{3}$ 与 $\delta-\mathrm{CsPbI}_{3}$ 晶体结构示意图 ${ }^{[73]}$; (b) $\mathrm{CsPbI}_{3}$ 量子点在空气中放置 $60 \mathrm{~d}$ 后的紫外-可见光谱 ${ }^{[74]}$; (c) $\mathrm{CHI}$ 裂缝填充界面工程示意图 ${ }^{[79] \text {; }}$ (d) PEAI 添加剂诱导 $\mathrm{CsPbI}_{3}$ 晶体生长示意图 ${ }^{\left[{ }^{[82}\right]}$

Figure 7 (a) Crystal structural diagrams of $\alpha-\mathrm{CsPbI}_{3}$ and $\delta-\mathrm{CsPb}_{3}{ }^{[73]}$; (b) UV-visible absorption of $\mathrm{CsPbI}_{3}$ QDs stored in ambient conditions for a period of $60 \mathrm{~d}^{[74]}$; (c) schematic illustration of crack-filling interface engineering ${ }^{[79]}$; (d) schematic for PEAI additive-induced CsPbI crystal growth $^{[82]}$ 


\subsection{3 元素掺杂稳定 $\mathrm{CsPbI}_{3}$}

元素掺杂可以使 $\mathrm{CsPbI}_{3}$ 晶体发生微应变, 稳定其立 方相. Xiang 等 ${ }^{[3]}$ 将 $\mathrm{Sb}$ 掺杂到 $\mathrm{CsPbI}_{3}$ 中, 由于 $\mathrm{Sb}^{3+}$ 离子 尺寸小于 $\mathrm{Pb}^{2+}$, 使晶体发生应变, 同时提高了晶体的相 稳定性和钙钛矿薄膜的形态. 并采用碳作对电极的无空 穴传输层(HTM)结构, 器件在空气中放置 $37 \mathrm{~d}$ 后效率为 原来的 $93 \%$. $\mathrm{Hu}$ 等 ${ }^{[84]}$ 将 $\mathrm{Bi}$ 掺杂到 $\mathrm{CsPbI}_{3}$ 中, 使 $\mathrm{CsPbI}_{3}$ 晶体中部分 $\mathrm{Pb}$ 被 $\mathrm{Bi}$ 取代, 由于 $\mathrm{Bi}$ 原子半径小于 $\mathrm{Pb}$ 原 子半径, 就会产生晶格微畸变, 使得形成的 $\mathrm{CsPb}_{1-}{ }_{-x} \mathrm{Bi}_{x} \mathrm{I}_{3}$ 在室温下稳定. 实现了当 $\mathrm{Bi}$ 的掺杂浓度为 $4 \mathrm{~mol} \%$ 时, 在空气中光伏效率达到 $13.21 \%$, 在空气中放置 $168 \mathrm{~h}$ 后 效率降为原来的 $68 \%$. Jena 等 ${ }^{[85]}$ 在 $\mathrm{CsPbI}_{3}$ 前驱液中加入 稀土元素 $\mathrm{Eu}$, 形成 $\mathrm{CsPbI}_{3}: x \mathrm{Eu}$, 退火温度只需要 $85{ }^{\circ} \mathrm{C}$, 有效降低了相转变的温度并且可以在空气中存在 $30 \mathrm{~d}$ 以上.

从上述可以看出, 相要阻止 $\mathrm{CsPbI}_{3}$ 钻钛矿的相变, 可以制成低对称性的黑色钙钛矿相, 如 $\beta$ 相和 $\gamma$ 相; 可 以减小晶体的尺寸, 无论是二维材料或是量子点; 通过 添加剂来保护其表面. 制备高质量的钙钛矿薄膜于器件 稳定性有重要的影响, 高质量致密的薄膜可以阻挡水分 进入晶体中, 减缓结晶过程有助于形成致密的薄膜. 用 半径较小的原子取代 $\mathrm{Pb}^{2+}$ 进行部分掺杂, 可以增加其容 许因子, 稳定晶体结构. 除此之外, 加强每个晶体之间 的连接, 阻止其发生连锁效应导致相变也是提高稳定性 的另一种方法.
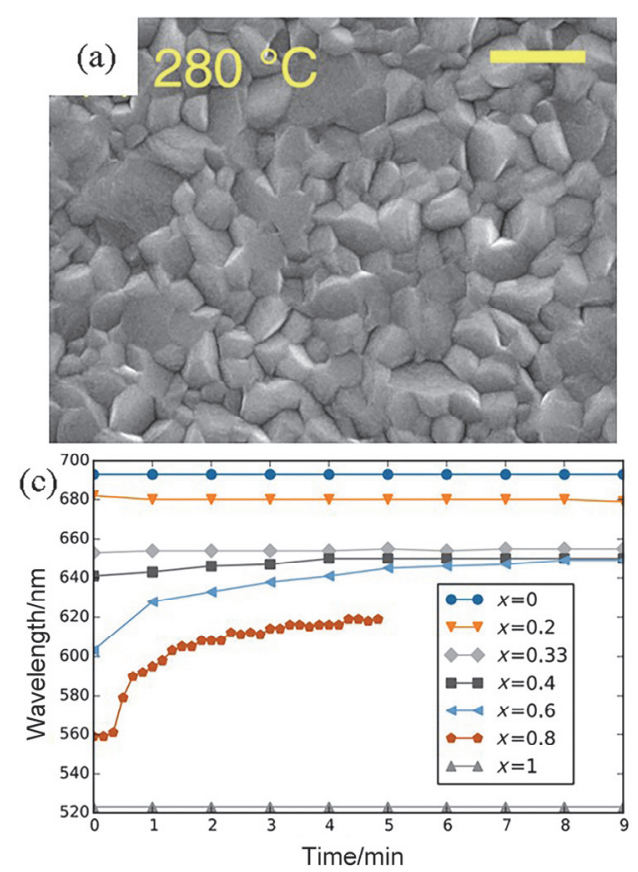

\section{$5.4 \mathrm{CsPbl}_{2} \mathrm{Br}$ 钙钛矿薄膜及器件稳定性改善方法}

将 $\mathrm{I}$ 用 $\mathrm{Br}$ 代替可以提高 $\mathrm{CsPbI}_{3}$ 钙钛矿晶体的容许 因子从而提高晶体的稳定性. 常见的 $\mathrm{Br}$ 掺杂的 $\mathrm{CsPbI}_{3}$ 为 $\mathrm{CsPbIBr}_{2}$ 与 $\mathrm{CsPbI}_{2} \mathrm{Br}$. $\mathrm{CsPbI}_{2} \mathrm{Br}$ 钙钛矿吸光材料在效 率与稳定性具有很好的平衡, 不会像 $\mathrm{CsPbI}_{3}$ 钙钛矿那样 在干燥的环境中也会迅速地从黑色相变为黄色相. $\mathrm{CsPbI}_{2} \mathrm{Br}$ 钙钛矿的禁带宽度为 $1.92 \mathrm{eV}$, 可以吸收小于 $650 \mathrm{~nm}$ 的太阳光, 器件的极限电流密度约为 17 $\mathrm{mA} / \mathrm{cm}^{2}$. $\mathrm{CsPbI}_{2} \mathrm{Br}$ 由于只有一个 $\mathrm{Br}$ 取代了 I 而形成, 并 没有使其容许因子达到 0.9 , 其在高湿度的环境下依旧 容易发生相变. Nam 等 ${ }^{[86]}$ 通过研究退火温度对 $\mathrm{CsPbI}_{2} \mathrm{Br}$ 薄膜结晶过程中的表面形态、晶体结构和化学状态的影 响, 发现退火温度对薄膜的稳定性及器件的光电效率影 响都很大, 在退火温度为 $280{ }^{\circ} \mathrm{C}$ 薄膜的质量最好, 表面 致密无孔(图 8a).

\subsection{1 掺杂稳定 $\mathrm{CsPbI}_{2} \mathrm{Br}$}

Yin 等 ${ }^{[87]}$ 将 $\mathrm{F}$ 元素掺杂到钻钛矿中形成 $\mathrm{CsPbBr}$ $\mathrm{I}_{2-}{ }_{x} \mathrm{~F}_{x}$, 这是首次尝试对钙钛矿中 $\mathrm{X}$ 位原子进行掺杂取 代. F 的加入改变钙钛矿晶体的容许因子, 并且还可能 形成一种体相异质结构, 使器件的稳定性提高, 在空气 中放置 $10 \mathrm{~d}$ 后，光电效率为原来的 $70 \%$ 左右. $\mathrm{Liu}$ 等 $^{[88]}$ 在前驱液中加入 $\mathrm{MnCl}_{2}, \mathrm{Mn}^{2+}$ 进入 $\mathrm{CsPbI}_{2} \mathrm{Br}$ 晶格的间隙 中, 抑制成核减缓结晶速率，获得了大颗粒致密薄膜，
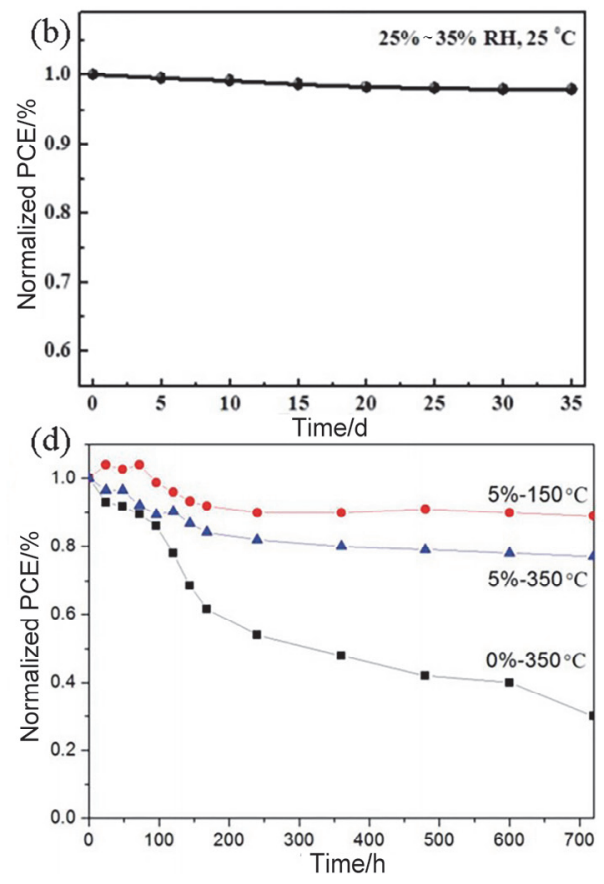

图 8 (a) $\mathrm{CsPbI}_{2} \mathrm{Br}$ 薄膜在 $280{ }^{\circ} \mathrm{C}$ 下退火的扫描电镜图像 ${ }^{[86]}$; (b) 无封装存储的最佳性能器件的长期稳定性 ${ }^{[88]}$; (c)在 1 太阳光照射下 $\mathrm{CsPb}\left(\mathrm{Br}_{x} \mathrm{I}_{1}-x\right)_{3}$ 光致发光峰位随时间的变化 ${ }^{[89]} ;$ (d) $\mathrm{CsPbI}_{2} \mathrm{Br}$ 组成 PSCs 在空气中放置 $30 \mathrm{~d}$ 效率衰减图 ${ }^{[91]}$

Figure 8 (a) SEM images of $\mathrm{CsPbI}_{2} \mathrm{Br}$ films annealed at the temperature of $280{ }^{\circ} \mathrm{C}^{[86]}$; (b) long-term stability of the best-performing device stored without encapsulation ${ }^{[88]}$; (c) photoluminescence peak position as a function of time for $\mathrm{CsPb}\left(\mathrm{Br}_{x} \mathrm{I}_{1-x}\right)_{3}$ materials under $c a$. 1 sun illumination ${ }^{[89]}$; (d) $\mathrm{CsPbI}_{2} \mathrm{Br}$ composition PSCs placement efficiency attenuation chart in air for $30 \mathrm{~d}^{[91]}$ 
同时减少了表面缺陷; 此外, 由于 $\mathrm{Cl}^{-}$疏水的原因, 可 以有效减少水分对钙钛矿薄膜的影响. 使得器件在 $25{ }^{\circ} \mathrm{C}, 25 \% \sim 35 \%$ 的相对湿度下放置超过 2 个月效率仍 保持原来的 $97 \%$ (图 $8 b$ ).

有研究表明, 钙钛矿材料会发生光致相偏析现象, 并且随着 $\mathrm{Br}$ 的增加, 光稳定性会减小. 同时, 已经有实 验表明光照会对 $\mathrm{CsPbI}_{2} \mathrm{Br}$ 的稳定性产生影响 ${ }^{[83]}$. McGehee 等 ${ }^{[89]}$ 首次研究了 $\mathrm{CsPb}\left(\mathrm{Br}_{x} \mathrm{I}_{1-x}\right)_{3}$ 这一类钙钛矿 薄膜的光稳定性. 发现当 $0 \leqslant x \leqslant 0.4$ 时, 薄膜的光稳定 性很好, 相较于有机-无机杂化钙钛矿 $\mathrm{MAPb}\left(\mathrm{Br}_{x} \mathrm{I}_{1}-x\right)_{3}$ $(0 \leqslant x \leqslant 0.2)$ 具有更好的稳定性; 当 $0.4<x<1$ 时, 光稳 定性会逐渐减弱(图 8c). Bach 等 ${ }^{[90]}$ 认为光照是 $\mathrm{CsPbI}_{2} \mathrm{Br}$ 器件产生迟滞效应的原因, 这是由于光照使富碘化物相 形成于晶界, 并以团族的形式分离, 这些离子最终在电 子传输层/钙钛矿层界面聚集, 阻碍电子的提取从而导 致器件的迟滞效应.

\subsection{2 钝化 $\mathrm{CsPbI}_{2} \mathrm{Br}$ 表面}

$\mathrm{Han}$ 等 $^{[91]}$ 在前驱液中加入 $\mathrm{CH}_{3} \mathrm{COO}^{-}, \mathrm{CH}_{3} \mathrm{COO}^{-}$控 制 $\mathrm{CsPbI}_{2} \mathrm{Br}$ 晶体生长用, 减小晶粒尺寸形成致密薄膜, 在退火后的晶界表面形成 $\mathrm{PbO}$ 钝化膜, 使制成的器件在 相对湿度 $20 \%$ 的空气中放置 $30 \mathrm{~d}$ 后仍能保持最初效率 的 90\%(图 6d). Zeng 等 ${ }^{[92]}$ 发现在 $\mathrm{CsPbI}_{2} \mathrm{Br}$ 上沉积一层 P3HT 薄膜可以有效减少表面缺陷, 从而减小载流子的 复合. 退火后可以将电压的损失降到 $0.5 \mathrm{eV}$, 器件在手 套箱中放置 $960 \mathrm{~h}$ 依旧可以保持原来效率的 $90 \%$.

$\mathrm{CsPb}_{2} \mathrm{Br}$ 薄膜质量、无缺陷结晶度和厚度决定了相 应器件的光伏性能. 通过对薄膜进行精确的生长控制及 后处理获得高质量薄膜; 通过界面工程, 获得大颗粒致 密层, 或增加缓冲层、阻挡层, 可以有效减小空气中的 水分对钙钛矿晶体的破坏, 从而提高钙钛矿薄膜及器件 的稳定性. $\mathrm{CsPbI}_{2} \mathrm{Br}$ 具有优良的长期稳定性和高的光吸 收能力, 通过发展新的制备技术和稳定晶体结构, 优化 组装工艺和消除相分离. 在光伏领域中显示出巨大的应 用潜力.

\section{$5.5 \mathrm{CsPbIBr}_{2}$ 钲钛矿薄膜及器件稳定性改善方法}

$\mathrm{CsPlBr}_{2}$ 吸光材料的禁带宽度为 $2.05 \mathrm{eV}$, 器件的极 限电流密度约为 $13.5 \mathrm{~mA} / \mathrm{cm}^{2}$, 由于 $\mathrm{Br}$ 与 $\mathrm{I}$ 的比例为 2 : 1 , 使得 $\mathrm{CsPbIBr}_{2}$ 器件具很好的稳定性, 但 $\mathrm{CsPb}\left(\mathrm{Br}_{x}-\right.$ $\left.\mathrm{I}_{1-x}\right)_{3}$ 中 $x>0.4$, 会发生光致相分 离 ${ }^{[89]}$, 而且器件的光电 转换效率一直很低, 所以采用 $\mathrm{CsPbIBr}_{2}$ 为吸光层制备器 件的研究较少. $\mathrm{Ma}$ 等 ${ }^{[93}$ 率先使用双源热蒸发方法制备 了结构为 $/ \mathrm{FTO} / \mathrm{c}-\mathrm{TiO}_{2} / \mathrm{CsPbIBr}_{2} / \mathrm{Au}$ 太阳能电池, 获得了 $4.7 \%$ 的光电转换效率. 限制 $\mathrm{CsPbIBr}_{2}$ 钙钛矿太阳能电池 效率的一个原因是在富 I 集中导致相分离. 为了解决此 问题, $\mathrm{Zhu}$ 等 ${ }^{[94]}$ 将 $\mathrm{CsI}$ 旋涂到 $\mathrm{CsPbIBr}$ 前驱体薄膜表面 (图 9a), 结果表明, 无 HTM, 碳基 $\mathrm{CsPbIBr}_{2}$ 钙钛矿器件 的效率达到了 $9.16 \%$, 这主要是由于优化了结晶度以及 减小了晶体的缺陷.
掺杂与界面修饰是改变结晶性能, 减少晶体缺陷的 的常用办法. Jiang 等 ${ }^{[95]}$ 使用 $\mathrm{CsAc}$ 和 $\mathrm{HPbX}_{3}$ 加入前驱液 中, 克服了 $\mathrm{CsBr}$ 溶解度低的问题, 从而制备了厚度为 $500 \mathrm{~nm}$ 的钲钛矿薄膜, 并使用苯乙基碘化胺(PEAI)钝化 表面, 形成的准二维钙钛矿明显降低了缺陷态密度, 得 到了 $1.19 \mathrm{~V}$ 的开路电压和 $9.5 \%$ 的光电转换效率. 目前, $\mathrm{CsPbIBr}_{2}$ 钙钛矿器件的最高效率是掺杂 $\mathrm{Sn}$ 的, 由于 $\mathrm{Sn}^{2+}$ 的掺杂改变了材料的禁带宽度, 使器件的电流密度 提高到了 $14.3 \mathrm{~mA} / \mathrm{cm}^{2}$, 最终光电转换效率达到了 $11.3 \%{ }^{[49]}$.

$\mathrm{CsPbIBr}_{2}$ 钙钛矿器件的稳定性较好, 但效率一直难 以提高, 尽管通过掺杂等方式调节结晶动力学, 改善缺 陷, 但器件的迟滞效应仍很严重, 为了进一步提高 $\mathrm{CsPbIBr}_{2}$ 钙钛矿器件的效率, 显著减小晶界和增大晶 粒尺寸对于有效的载流子提取和转移, 特别是降低能量 损耗至关重要.

\section{6 $\mathrm{CsPbBr}_{3}$ 钙钛矿薄膜及器件稳定性改善方法}

将 $\mathrm{I}$ 全部用 $\mathrm{Br}$ 取代所形成的 $\mathrm{CsPbBr}$ 钙钛矿材料在 室温下呈现正交相, 在 $88{ }^{\circ} \mathrm{C}$ 时转变为四方相, 在 $130{ }^{\circ} \mathrm{C}$ 时转变为黄橙色的立方相 ${ }^{[96]}$, 整个转变过程颜 色无明显变化. 这是在空气湿度下最稳定的无机钙钛矿 材料. 但 $\mathrm{CsPbBr}_{3}$ 钙钛矿的禁带宽度为 $2.3 \mathrm{eV}$, 导致其只 能吸收波长小于 $550 \mathrm{~nm}$ 的太阳光, 器件的极限电流密 度约为 $9 \mathrm{~mA} / \mathrm{cm}^{2}$. Kulbak 等 ${ }^{[97]}$ 首次以 $\mathrm{CsPbBr}_{3}$ 为吸光层 做成无机钙钛矿太阳能电池器件, 器件开路电压为 1.3 $\mathrm{V}$, 效率为 $4.09 \%$, 远远低于 $\mathrm{CsPbI}_{3}$ 体系. 因此对 $\mathrm{CsPb}-$ $\mathrm{Br}_{3}$ 体系的研究主要集中在器件新结构的设计, 以期提 高其光电性能及进一步改善其稳定性.

Spiro-MeOTAD 是目前无机杂化钙钛矿太阳能电池 常用的空穴传输层(HTM)材料. 但却难以用于 $\mathrm{CsPbBr}_{3}$ 无机钲钛矿太阳能电池制备高效器件, 其效率仅仅在 $4 \% \sim 5 \%$ 左右，原因可能是 Spiro-MeOTAD 空穴传输层 使用了吸湿性强的 Li-TFSI, 导致钲钛矿的不稳定(图 9b). 因此, 研究者们期望通过制备无空穴传输层的无 机钙钛矿太阳能电池以避免这一问题. Liang 等 ${ }^{[98]}$ 在 $\mathrm{CsPbBr}_{3}$ 上直接沉积碳作为空穴传输层以及对电极, 其 器件结构为: $\mathrm{FTO} / c-\mathrm{TiO}_{2} / m-\mathrm{TiO}_{2} / \mathrm{CsPbBr} /$ carbon, 光电 转化效率为 $6.7 \%$, 并且在高温和低温下都表现出超越 杂化钙钛矿太阳能电池的优异稳定性. 在 $25{ }^{\circ} \mathrm{C}$, 相对 湿度 $95 \%$ 的空气中无封装放置 3 个月 $(2640 \mathrm{~h})$ 其效率依 然未减小(图 9c). 碳可以有效阻挡水分进入钙钛矿层. 用廉价的碳代替了昂贵的空穴传输层并提高了效率，这 种方法为钙钛矿的研究提供了新思路. 表 2 列出了不同 类型无机钙钛矿太阳能电池在不同环境下的稳定性能.

综上, 我们可以看出无机钲钛矿的化学稳定性与热 稳定性要比有机一无机杂化钙钛矿好, 但无机钙钛矿晶 体本身具有热力学不稳定的性质, 在潮湿的环境中很容 易发生相变, 从立方相变为非钙钛矿的正交相. 研究者 
(a)

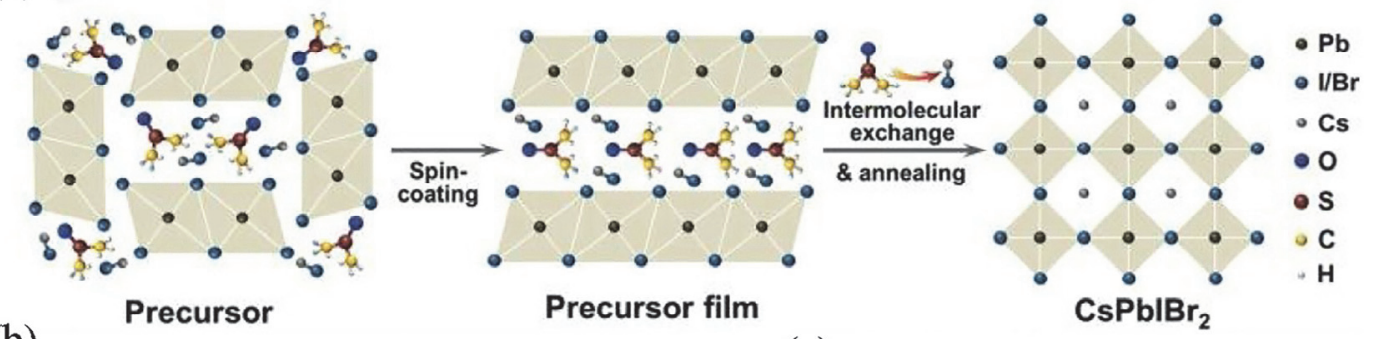

(b)

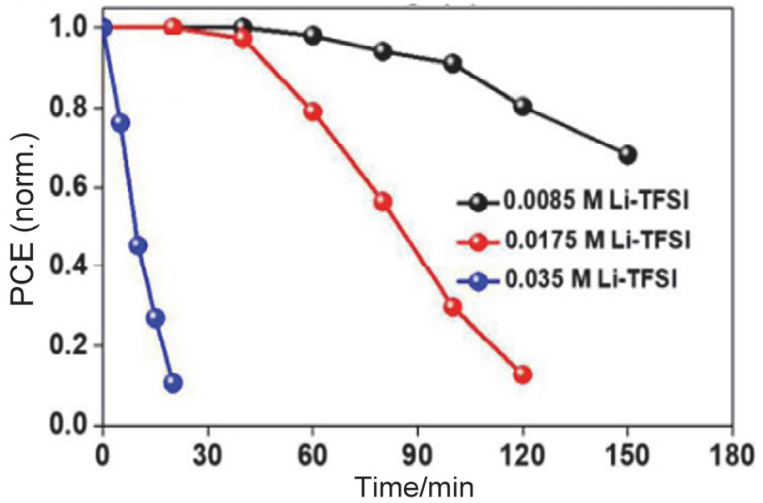

(c)

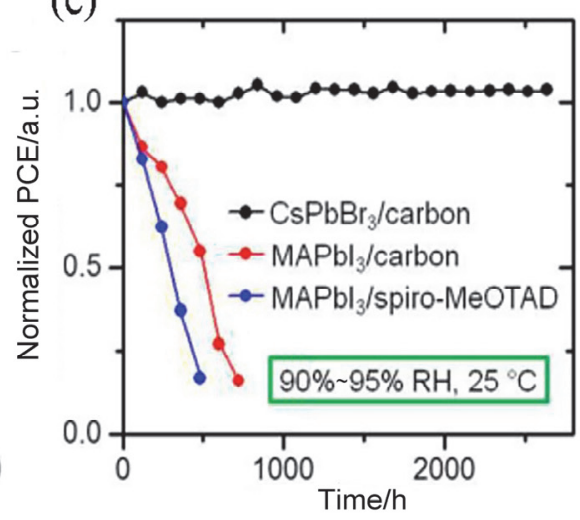

图 9 (a)分子间交换示意图 ${ }^{[94]}$; (b) 在相对湿度 35\% 40\%的空气中不同 $\mathrm{Li}$ 掺杂 $\mathrm{HTM}$ 器件的稳定性 ${ }^{[99]}$; (c) $\mathrm{CsPbBr}_{3} / \mathrm{carbon}$ 与 $\mathrm{MAPbI}_{3} / \mathrm{carbon}$ 和 $\mathrm{MAPbI}_{3} /$ spiro-MeOTAD 组成 PCSs 的稳定性比较图 ${ }^{[98]}$

Figure 9 (a) Illustration of intermolecular exchange strategy ${ }^{[94]}$; (b) stability of HTM dped with different Li of device in ar with relative hmidity of $35 \% \sim 40 \%{ }^{[99]}$; (c) normalized PCEs of $\mathrm{CsPbBr}_{3} /$ carbon based all-inorganic PSCs, $\mathrm{MAPbI}_{3} /$ carbon and $\mathrm{MAPbI}_{3} / \mathrm{spiro}-\mathrm{MeOTAD}$ based hybrid PSCs ${ }^{[98]}$

表 2 不同类型无机钙铁矿太阳能电池稳定性能表

Table 2 Stability performance table for different types of inorganic perovskite devices

\begin{tabular}{|c|c|c|c|c|c|}
\hline Perovskite & Device structure & Test condition & Time/h & Initial PCE/\% degradation & Ref. \\
\hline \multirow[t]{8}{*}{$\mathrm{CsPbI}_{3}$} & $\mathrm{FTO} / \mathrm{TiO}_{2} / \mathrm{CsPbI}_{3} \mathrm{QD} /$ Spiro-MeOTAD/MoO $/ \mathrm{Al}$ & Ambient & 1440 & $10.77 \% / 0 \%$ & [74] \\
\hline & $\mathrm{FTO} / \mathrm{TiO}_{2} / \mathrm{CsPbI}_{3} \mathrm{QD} / \mathrm{PTAA} / \mathrm{Au}$ & $\mathrm{N}_{2}$ & 720 & $11.64 \% / 2 \%$ & [76] \\
\hline & $\mathrm{FTO} / \mathrm{TiO}_{2} / \mathrm{CsPbI}_{3} / \mathrm{Spiro}-\mathrm{MeOTAD} / \mathrm{Ag}$ & $30 \% \mathrm{RH}$ & 72 & $4.13 \% / 25 \%$ & [78] \\
\hline & $\mathrm{ITO} / \mathrm{PTAA} / \mathrm{CsPb}_{3} / \mathrm{PCBM} / \mathrm{C} 60 / \mathrm{BCP} / \mathrm{Al}$ & Ambient & 720 & $11.4 \% / 15 \%$ & {$[81]$} \\
\hline & $\mathrm{FTO} / \mathrm{TiO}_{2} / \mathrm{CsPbI}_{3} / \mathrm{PTAA} / \mathrm{Au}$ & $20 \% \sim 30 \% \mathrm{RH}$ & 1440 & $15.07 \% / 8 \%$ & [82] \\
\hline & $\mathrm{FTO} / c-\mathrm{TiO}_{2} / m-\mathrm{TiO}_{2} / \mathrm{CsPb}_{0.96} \mathrm{Sb}_{0.04} \mathrm{I}_{3} /$ Carbon & $20 \% \mathrm{RH}$ & 888 & $5.18 \% / 7 \%$ & [83] \\
\hline & $\mathrm{FTO} / c-\mathrm{TiO}_{2} / \mathrm{CsPb}_{0.96} \mathrm{Bi}_{0.04} \mathrm{I}_{3} / \mathrm{CuI} / \mathrm{Au}$ & $55 \% \mathrm{RH}$ & 68 & $13.21 \% / 32 \%$ & [84] \\
\hline & $\mathrm{FTO} / \mathrm{TiO}_{2} / \mathrm{CsPbI}_{3}: x \mathrm{Eu} /$ Spiro-MeOTAD/Au & Ambient & 720 & $6.8 \% /-$ & [85] \\
\hline \multirow[t]{5}{*}{$\mathrm{CsPbI}_{2} \mathrm{Br}$} & $\mathrm{FTO} / c-\mathrm{TiO}_{2} / m-\mathrm{TiO}_{2} / \mathrm{CsPbBr}_{1.78} \mathrm{~F}_{0.22} /$ Spiro-MeOTAD $/ \mathrm{Au}$ & $20 \% \mathrm{RH}$ & 240 & $10.26 \% / 30 \%$ & {$[87]$} \\
\hline & $\mathrm{FTO} / \mathrm{TiO}_{2} / \mathrm{CsPbBI}_{2} / \mathrm{QDs} / \mathrm{PTAA} / \mathrm{Au}$ & $20 \% \sim 35 \% \mathrm{RH}$ & 840 & $13.47 \% / 3 \%$ & {$[88]$} \\
\hline & $\mathrm{FTO} / c-\mathrm{TiO}_{2} / m-\mathrm{TiO}_{2} / \mathrm{CsPbBrI} / /$ Spiro-MeOTAD $/ \mathrm{Au}$ & $20 \% \mathrm{RH}$ & 720 & $12.0 \% / 10 \%$ & [91] \\
\hline & $\mathrm{ITO} / \mathrm{TiO}_{2} / \mathrm{CsPbBr} / 2 / \mathrm{P} 3 \mathrm{HT} / \mathrm{Au}$ & $\mathrm{N}_{2}$ & 960 & $12.02 \% / 10 \%$ & [92] \\
\hline & $\mathrm{FTO} / \mathrm{TiO}_{2} / \mathrm{CsPbI}_{2} \mathrm{Br} / \mathrm{CsPbI} 2 \mathrm{Br} \mathrm{QDs} / \mathrm{PTAA} / \mathrm{Au}$ & $20 \% \sim 30 \% \mathrm{RH}$ & 720 & $14.81 \% / 5 \%$ & [100] \\
\hline \multirow[t]{3}{*}{$\mathrm{CsPbIBr}_{2}$} & $\mathrm{ITO} / \mathrm{SnO}_{2} / \mathrm{CsPbIBr}_{2} / \mathrm{Spiro}-\mathrm{MeOTAD} / \mathrm{Au}$ & Ambient & 250 & $9.5 \% / 1 \%$ & [95] \\
\hline & $\mathrm{FTO} / m-\mathrm{TiO}_{2} / \mathrm{CsPb}_{0.9} \mathrm{Sn}_{0.1} \mathrm{IBr}_{2} /$ Carbon & Ambient & 2800 & $11.3 \% / 0 \%$ & [49] \\
\hline & $\mathrm{FTO} / \mathrm{TiO}_{2} / \mathrm{CsPbIBr}_{2} /$ Carbon & Ambient & - & $8.6 \% /-$ & [101] \\
\hline \multirow[t]{3}{*}{$\mathrm{CsPbr}_{3}$} & $\mathrm{FTO} / c-\mathrm{TiO}_{2} / m-\mathrm{TiO}_{2} / \mathrm{CsPbBr}_{3} /$ carbon & $90 \% \sim 95 \% \mathrm{RH}$ & 2640 & $6.7 \% / 0 \%$ & [98] \\
\hline & $\mathrm{FTO} / c-\mathrm{TiO}_{2} / m-\mathrm{TiO}_{2} / \mathrm{GQDs} / \mathrm{CsPb}_{0.97} \mathrm{~Tb}_{0.03} \mathrm{Br}_{3} / \mathrm{SnS}: \mathrm{ZnS} /$ Carbon & $80 \% \mathrm{RH}$ & 960 & $10.26 \% / 2 \%$ & {$[63]$} \\
\hline & $\mathrm{FTO} / c-\mathrm{TiO}_{2} / m-\mathrm{TiO}_{2} / \mathrm{GQDs} / \mathrm{CsPbBr} /$ Carbon & $90 \% \mathrm{RH}$ & 3120 & $9.72 \% / 13 \%$ & [42] \\
\hline
\end{tabular}

们也提出来各种办法来稳定其晶体结构, 包括溶剂工 程、界面工程、表面针化、制成量子点或准二维材料, 元 素掺杂等等, 如图 10 所示. 由于 $\mathrm{CsPbI}_{3} 、 \mathrm{CsPbI}_{2} \mathrm{Br}$ 、
$\mathrm{Cs} \mathrm{PbIBr}_{2} 、 \mathrm{CsPbBr}_{3}$ 这四种类型的无机钙钛矿吸光材料 的性质不同, 稳定性好的器件效率低, 而器件效率高的 稳定性差. 针对不同材料选择相应的优化方法, 充分发 

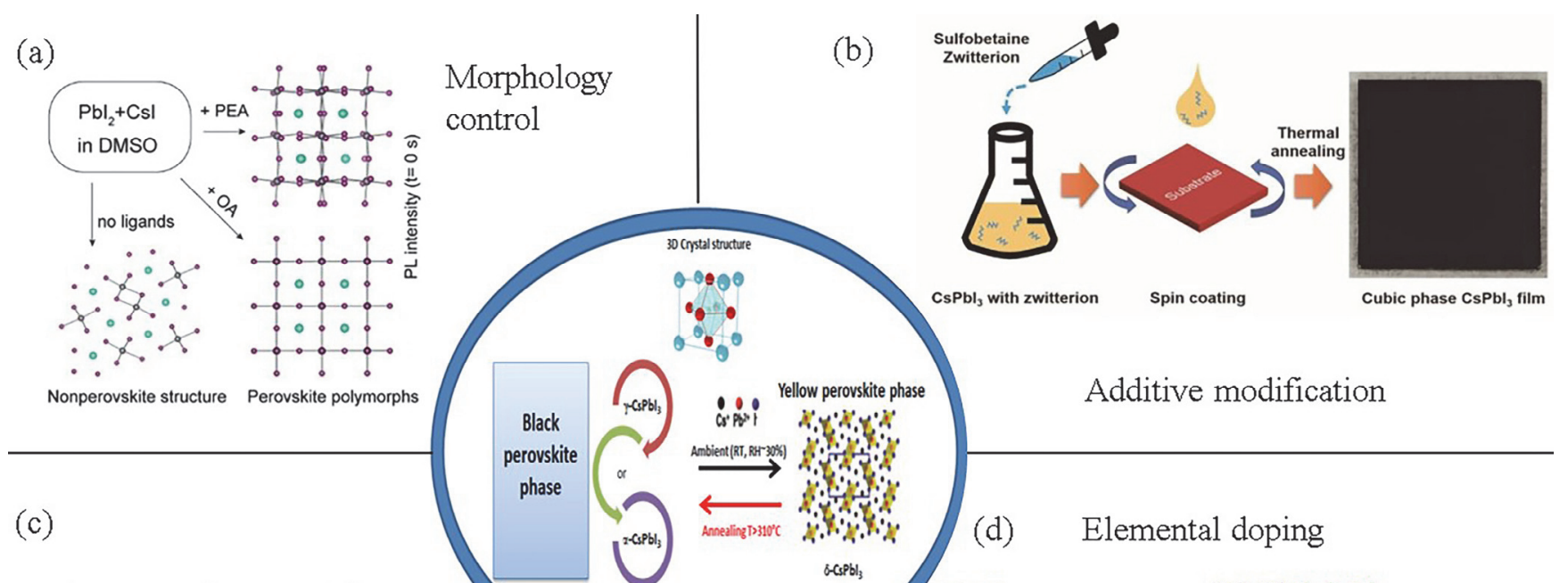

(c)

Quantum dot material
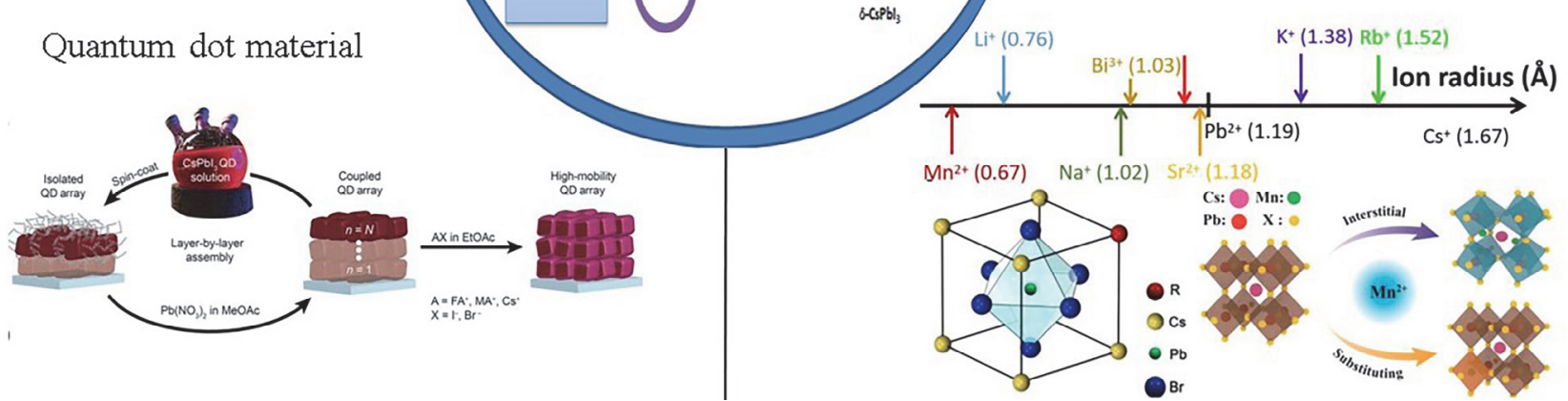

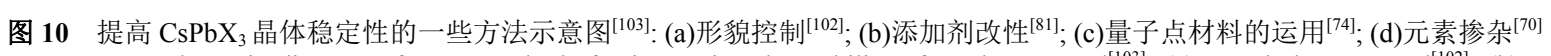

Figure 10 Schematic diagram of some methods for improving the stability of $\mathrm{CsPbX}_{3}$ crystal $^{[103]}$ : (a) morphology control ${ }^{[102]}$; (b) additive modification $^{[81]} ;$ (c) application of quantum dot material ${ }^{[74]}$; (d) elemental doping ${ }^{[70]}$

挥材料的优势, 弥补材料的劣势, 对于无机钙钛矿太阳 能电池的发展是至关重要的.

\section{6 总结与展望}

全无机钙铁矿太阳能电池相对于有机一无机杂化钲 钛矿太阳能电池, 它们具有更好的光、热稳定性. 以 $\mathrm{CsPb}_{3}$ 为结构的含铅无机钙钛矿太阳能电池的光电转 化效率已经超过了 $19 \%$. 具有非常好的发展潜力, 但因 其晶体结构所导致的晶相不稳定还未得到有效的解决, 此外, 部分无机钙钛矿的禁带宽度较宽, 对太阳光的利 用率较低. 在今后的研究中, 应将重点放在以下几个方 面:

(1)无机钙钛矿晶体的相稳定是最大的难题与挑战, 使用小半径原子进行掺杂是比较简单的改善办法; 低维 材料、表面钝化来降低缺陷态密度, 提高稳定性等也逐 渐成为主要的改进手段. 此外, 即使封装后的器件依然 会受到水分的侵蚀, 不仅要提高吸光层的稳定性, 还要 优化电子传输层(ETM)与空穴传输层(HTM)的稳定性, 在整体上提高器件的稳定性.

(2) 目前大多数研究都集中在吸光材料的优化上, 对无机钙铁矿太阳能电池的工作机理缺乏研究. 深入探 究其器件的电荷传输与复合的理论, 建立一套完整的理 论体系, 对于提高器件的性能和稳定性都有很重要的意 义。
(3) 目前大多数高效率钙钛矿太阳能电池都含有有 害元素 $\mathrm{Pb}$, 对人体和环境均有影响. 研究者们也在积极 地探究无铅钙钣矿, 但其效率一直很低. 进一步研究新 型无铅钙铁矿太阳能电池是未来发展的必要趋势.

(4)关于大面积制备与柔性器件的问题. 目前实验 室大多数的器件面积为 $0.1 \mathrm{~cm}^{2}$ 左右, 䥻钛矿太阳能电 池若想商业化大面积制备是必要的; 而柔性器件作为钙 钛矿的一大优势, 为今后制备可穿戴器件提供了基础, 目前在无机钙钛矿领域的研究较少, 今后应在此领域做 出更多的研究.

\section{作者简介}

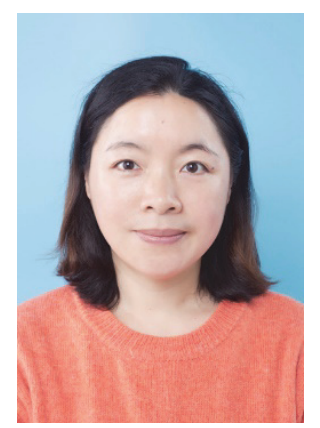

杨英, 副教授, 武汉大学博士毕业. 长期从事材料物理化 学及新能源材料与器件的科研工作, 对固态高分子电解质以 及固态染料敏化太阳能电池、量子点太阳能电池及钙钛矿太 阳能电池有夯实的理论和实践基础. 于 2013 2014 年间美国 
怀俄明大学完成博士后研究工作. 现工作于中南大学冶金与 环境学院. 主要研究方向: 新能源材料与器件.

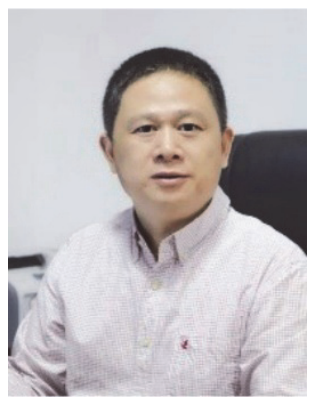

郭学益, 教授, 1995 年于中南大学获得博士学位. 1997 年 完成博士后研究工作, 1999 2000 年在日本佐贺大学理工学 部机能物质化学科担任研究员, 2000 2003 年在日本东京大 学国际产学共同研究中心担任客员教授. 现工作于中南大学 冶金与环境学院. 主要研究方向: 资源循环利用及环境材料.

\section{References}

[1] Hodes, G. Science 2013, 342, 317.

[2] Liu, C.; Li, W.; Zhang, C.; Ma, Y.; Fan, J.; Mai, Y. J. Am. Chem. Soc. 2018, 140, 3825 .

[3] Lee, M.; Teuscher, J.; Miyasaka, T.; Murakami, T. N.; Snaith, H. J. Science 2013, 338, 643.

[4] Heo, J. H.; Im, S. H.; Noh, J. H.; Mandal, T. N.; Lim, C. S.; Chang, J. A.; Lee, Y. H.; Kim, H. J.; Sarkar, A. Nat. Photonics 2013, 7, 486.

[5] Guo, X. D.; Niu, G. D.; Wang, L. D. Acta Chim. Sinica 2015, 73, 211 (in Chinese). (郭旭东, 牛广达, 王立铎, 化学学报, 2015, 73, 211.)

[6] Chen, X.; Xie, J.; Wang, W.; Yuan, H.; Xu, D.; Zhang, D.; He, Y.; Shen, H. Acta Chim. Sinica 2019, 77, 9 (in Chinese). (陈薪羽, 解俊 杰, 王炜, 袁慧慧, 许頔, 张悲, 何云龙, 沈沪江, 化学学报, 2019, 77, 9.)

[7] Yang, Y.; Chen, T.; Pan, D.; Zhang, Z.; Guo, X. Acta Chim. Sinica 2018, 76, 681 (in Chinese). (杨英, 陈甜, 潘德群, 张政, 郭学益, 化学学报, 2018, 76, 681.)

[8] Wu, M.; Liu, S.; Chen, H.; Wei, X.; Li, M.; Yang, Z.; Ma, X. Acta Chim. Sinica 2018, 76, 49 (in Chinese). (吴苗苗, 刘世强, 陈浩, 魏雪虎，李洺阳，杨志宾，马向东，化学学报, 2018, 76, 49.)

[9] https://www.nrel.gov/pv/assets/images/thumb-best-research-cellefficiencies-190416.png accessed July 2019.

[10] Koh, T. M.; Fu, K.; Fang, Y.; Chen, S.; Sum, T. C.; Mathews, N.; Mhaisalkar, S. G.; Boix, P. P.; Baikie, T. J. Phys. Chem. C 2014, 118, 16458.

[11] Aharon, S.; Dymshits, A.; Rotem, A.; Etgar, L. J. Mater. Chem. A 2015, 3, 9171 .

[12] Fu, Y.; Zhu, H.; Schrader, A. W.; Liang, D.; Ding, Q.; Joshi, P.; Wang, L. H.; Zhu, X.; Jin, S. Nano Lett. 2016, 16, 1000.

[13] Lee, J.; Kim, D.; Kim, H.; Seo, S.; Cho, S. M.; Park, N. Adv. Energy Mater. 2015, 5, 1501310.

[14] Saliba, M.; Matsui, T.; Seo, J. Y.; Domanski, K.; Correa-Baena, S. M.; Tress, W.; Abate, A.; Hagfeldt, A.; Grätzel, M. Energy Environ. Sci. 2016, 9, 1989.

[15] Smith, I. C.; Hoke, E. T.; Solis-Ibarra, D.; McGehee, M. D.; Karunadasa, H. I. Angew. Chem., Int. Ed. 2014, 53, 11232.

[16] Guarnera, S.; Abate, A.; Zhang, W.; Foster, J. M.; Richardson, G.; Petrozza, A.; Snaith, H. J. J. Phys. Chem. Lett. 2015, 6, 432.

[17] Hwang, I.; Jeong, I.; Lee, J.; Ko, M. J.; Yong, K. ACS Appl. Mater. Interfaces 2015, 7, 17330.

[18] Yang, Y.; Wang, W. J. Power Sources 2015, 293, 577.

[19] Yang, Y.; Chen, T.; Pan, D.; Gao, J.; Zhu, C.; Lin, F.; Zhou, C.; Tai, Q.; Xiao, S.; Yuan, Y.; Dai, Q.; Han, Y.; Xie, H.; Guo, X. Nano Energy 2020, 47, 104246.

[20] Wang, D.; Wright, M.; Elumalai, N. K.; Uddin, A. Sol. Energy Mater. 2016, 147,255

[21] Park, N. G.; Grätzel, M.; Miyasaka, T.; Zhu, K.; Emery, K. Nature Energy 2016, 1, 16152

[22] Kim, H. S.; Seo, J. Y.; Park, N. G. ChemSusChem 2016, 9, 2528.
[23] Manser, J. S.; Saidaminov, M. I.; Christians, J. A.; Bakr, O. M.; Kamat, P. V. Acc. Chem. Res. 2016, 49, 330.

[24] Chen, Z.; Wang, J.; Ren, Y.; Yu, C.; Shum, K. Appl. Phys. Lett. 2012, $101,093901$.

[25] Kulbak, M.; Cahen, D.; Hodes, G. J. Phys. Chem. Lett. 2015, 6, 2452.

[26] Niezgoda, J. S.; Foley, B. J.; Chen, A. Z.; Choi, J. J. ACS Energy Lett. 2017, 2, 1043.

[27] Frolova, L. A.; Anokhin, D. V.; Piryazev, A. A.; Luchkin, S. Y.; Dremova, N. N.; Stevenson, K. J.; Troshin, P. A. J. Phys. Chem. Lett. 2017, 8, 67 .

[28] Chen, C.; Lin, H.; Chiang, K.; Tsai, W.; Huang, Y.; Tsao, C.; Lin, H. Adv. Mater. 2017, 29, 1605290 .

[29] Nam, J. K.; Jung, M. S.; Chai, S. U.; Choi, Y. J.; Kim, D.; Park, J. H. J. Phys. Chem. Lett. 2017, 8, 2936.

[30] Nam, J. K.; Chai, S. U.; Cha, W.; Choi, Y. J.; Kim, W.; Jung, M. S.; Kwon, J.; Kim, D.; Park, J. H. Nano Lett. 2017, 17, 2028.

[31] Wang, Y.; Liu, X.; Zhang, T.; Wang, X.; Kan, M.; Shi, J.; Zhao, Y. Angew. Chem., Int. Ed. 2018, 58, 16691.

[32] Liu, C.; Li, W.; Chen, J.; Fan, J.; Mai, Y.; Schropp, R. E. Nano Energy 2017, 41, 75 .

[33] Jiang, J. X.; Wang, Q.; Jin, Z. W.; Zhang, X. S.; Lei, J.; Bin, H. J.; Zhang, Z.; Li, Y.; Liu, S. Adv. Energy Mater. 2018, 8, 1701757.

[34] Giustino, F.; Snaith, H. J. ACS Energy Lett. 2016, 1, 1233.

[35] Li, Z.; Yang, M. J.; Park, J. S.; Wei, S. H.; Berry, J. J.; Zhu, K. Chem. Mater. 2016, 28, 284

[36] Marchioro, A.; Teuscher, J.; Friedrich, D.; Kunst, M.; Krol, R.; Moehl, T.; Gratzel, M.; Moser, J. E. Nat. Photonics 2014, 8, 250.

[37] Yang, W.; Noh, J.; Jeon, J.; Kim, Y.; Ryu, S.; Seo, J.; Seok, S. Science 2015, 348, 1234.

[38] Wang, P. Y.; Zhang, X. W.; Zhou, Y. Q.; Jiang, Q.; Ye, Q. F.; Chu, Z.; Li, X. X.; Yang, X. L.; Yin, Z. G.; You, J. B. Nat. Commun. 2018, 9, 2225 .

[39] Yin, G.; Zhao, H.; Jiang, H.; Yuan, S. H.; Niu, T. Q.; Zhao, K.; Liu, Z.; Liu, S. Adv. Funct. Mater. 2018, 1803269.

[40] Chen, W.; Chen, H.; Xu, G.; Xue, R.; Wang, S.; Li, Y.; Li, Y. Joule 2018, $10,011$.

[41] Wang, Z.; Liu, X.; Lin, Y.; Liao, Y.; Wei, Q.; Chen, H.; Qiu, J.; Chen, Y.; Zheng, Y. J. Mater. Chem. A 2019, 7, 2773.

[42] Duan, J.; Zhao, Y.; He, B.; Tang, Q. Angew. Chem., Int. Ed. 2018, $57,3787$.

[43] Yu, B.; Zhang, H.; Wu, J.; Li, Y.; Meng, Q. J. Mater. Chem. A 2018 6,19810

[44] Cho, F. J.; Deng, X. F.; Ma, Q. S.; Zheng, J. H.; Jae, S. Y. ACS Energy Lett. 2016, 1, 573 .

[45] Ma, Q. S.; Huang, S. J.; Wen, X. M.; Martin, A. G.; Anita, W. Y. Adv. Energy Mater. 2016, 6, 1502202.

[46] Lei, J.; Gao, F.; Wang, H. X.; Li, J.; Jiang, J.; Wu, X.; Gao, R.; Yang, Z.; Liu, S. Sol. Energy Mater. Sol. Cells 2018, 187, 1.

[47] Jae, K. N.; Sung, U. K.; Cha, W.; Choi, Y. J.; Kim, W. J. Nano Lett. 2017, 17, 2028

[48] Guo, Y.; Zhao, F.; Tao, J.; Jiang, J.; Zhang, J.; Yang, J.; Hu, Z.; Chu, J. ChemSusChem 2018, 2, 690.

[49] Liang, J.; Zhao, P. Y.; Wang, C. X.; Wang, Y. R.; Hu, Y.; Zhu, G. Y.; Ma, L. B.; Liu, J.; Jin, Z. J. Am. Chem. Soc. 2017, 139, 14009.

[50] Yang, F.; Daisuke, H.; Gaurav, K.; Muhammad, A. K.; Chi, H. N.; Zhang, Y. H.; Shen, Q.; Hayase, S. Z. Angew. Chem., Int. Ed. 2018, $57,12745$.

[51] Duan, J.; Zhao, Y.; Yang, X.; Wang, Y.; He, B.; Tang, Q. Adv. Energy Mater. 2018, 8, 1802346.

[52] Xiang, W. C.; Wang, Z. W.; Kubicki, D. J.; Tress, W. G.; Luo, J. S.; Daniel, P.; Seckin, A. Joule 2019, 3, 205.

[53] Cho, F. J. L.; Deng, X. F.; Zheng, J. H.; Kim, J.; Zhang, Z. L.; Zhang, M. J. Mater. Chem. A 2018, 6, 5580.

[54] Fai, C.; Lau, J.; Zhang, M.; Deng, X. F.; Zheng, J.; Bing, J. M.; Ma, Q. S.; Kim, J.; Hu, L.; Huang, S. ACS Energy Lett. 2017, 2, 2391.

[55] Li, Y.; Huang, Y.; Wei, J.; Liu, F.; Shao, Z.; Hu, L.; Chen, S.; Yang, S.; Tang, J.; Yao, J.; Dai, S. Nanoscale 2015, 7, 9902.

[56] Guo, X. Y.; Gao, J.; Zhang, Z.; Xiao, S.; Pan, D. Q.; Zhou, C. H.; Shen, J. Q.; Hong, J. B.; Yang, Y. Mater. Today Energy 2017, 5, 320.

[57] Zhang, Z.; Yang, Y.; Gao, J.; Xiao, S.; Zhou, C. H.; Pan, D. Q.; Liu, G.; Guo, X. Y. Mater. Today Energy 2017, 7, 27.

[58] Yang, Y.; Pan, D. Q.; Zhang, Z.; Chen, T.; Xie, H. Y.; Gao, J.; Guo, X. Y. J. Alloys. Compd. 2018, 766, 925.

[59] Yang, Y.; Gao, J.; Zhang, Z.; Xiao, S.; Xie, H. H.; Sun, Z. B.; Wang, 
J. H.; Zhou, C. H.; Wang, Y. W.; Guo, X. Y.; Chu, P. K.; Yu, X. F. Adv. Mater. 2016, 28, 8937.

[60] Yuan, H.; Zhao, Y.; Duan, J.; He, B.; Jiao, Z.;Tang, Q. Electrochim. Acta 2018, 279, 84

[61] Yan, L.; Xue, Q.; Liu, M.; Zhu, Z.; Tian, J.; Li, Z.; Chen, Z.; Chen, Z.; Yan, H. Adv. Mater. 2018, 1802509.

[62] Kulbak, M.; Gupta, S.; Kedem, N.; Levine, I.;Bendikov, T.; Hodes, G.; Cahen, D. J. Phys. Chem. Lett. 2016, 7, 167.

[63] Yuan, H.; Zhao, Y.; Duan, J.; Wang, Y..; Ynag, X.; Tang, Q. J. Mater. Chem. A 2018, 6, 24324.

[64] Wang, Y.; Zhang, T.; Kan, M.; Zhao, Y. J. Am. Chem. Soc. 2018, 140, 12345.

[65] Shen, E.; Chen, J.; Tian, Y.; Luo, Y.; Shen, Y.; Sun, Q.; Jin, T.; Shi, G.; Li, Y.; Tang, J. Adv. Sci. 2019, 1901952.

[66] Bai, D.; Bian, H.; Jin, Z.; Wang, H.; Meng, L.; Wang, Q.; Liu, S. Nano Energy 2018, 52, 408.

[67] Aristidou, N.; Eames, C.; Sanchez-Molina, I.; Bu, X.; Kosco, J.; Islam, M. S.; Haque, S. A. Nat. Commun. 2017, 8, 15218.

[68] Stoumpos. C. C.; Kanatzidis, M. G. Acc. Chem. Res. 2015, 48, 2791.

[69] Xiao, S.; Li, Z.; Guthrey, H.; Moseley, J.; Yang, Y.; Wozny, S.; Moutinho, H.; To, B.; Berry, J.; Gorman, B.; Yan, Y.; Zhu, K.; Al-Jassim, M. J. Phys. Chem. C 2015, 119, 26904.

[70] Duan, J.; Xu, H.; Sha, W.; Zhao, Y.; Wang, Y.; Yang, X.; Tang, Q. J. Mater. Chem. A 2019, 7, 21036.

[71] Travis, W.; Glover, E. N. K.; Bronstein, H.; Scanlon, D. O.; Palgrave, R. G. Chem. Sci. 2016, 7, 4548.

[72] Ahmad, W.; Khan, J.; Niu, G. D.; Tang, J. Sol. RRL. 2017, 1, 1700048.

[73] Eperon, G. E.; Paterno, G. M.; Sutton, R. J.; Zampetti, A.; Haghighirad, A. A.; Cacialli, F.; Snaith, H. J. J. Mater. Chem. A 2015, 3, 19688.

[74] Swarnkar, A.; Marshall, A. R.; Sanehira, E. M.; Chernomordik, B. D.; Moore, D. T.; Christians, J. A.; Chakrabarti, T.; Luther, J. M. Science 2016, 354, 92.

[75] Sanehira, E. M.; Marshall, A. R.; Christians, J. A.; Harvey, S. P.; Ciesielski, P. N.; Wheeler, L. M.; Schulz, P.; Lin, L. Y.; Beard, M. C.; Luther, J. M. Sci. Adv. 2017, 3, eaao4204.

[76] Wang, Q.; Jin, Z.; Chen, D.; Bai, D.; Bian, H.; Sun, J.; Zhu, G.; Wang, G.; Liu, S. Adv. Energy Mater. 2018, 1800007.

[77] Smith, L. C.; Hoke, D.; Solis-Ibarra, D.; McGehee, M.; Karunadasa, H. Angew. Chem., Int. Ed. 2014, 53, 11232.

[78] Luo, P.; Xia, W.; Zhou, S. W.; Sun, L.; Cheng, J.; Xu, C.; Lu, Y. J. Phys. Chem. Lett. 2016, 7, 3603.

[79] Wang, Y.; Dar, M. I.; Ono, L.; Zhang, T.; Kan, M.; Li, Y.; Zhang, L.; Wang, X.; Yang, Y.; Gao, X.; Qi, Y.; Grätzel, M.; Zhao, Y. Science 2019, 365, 591.

[80] Fu, Y.; Rea, M. T.; Chen, J.; Morrow, D. J.; Hautzinger, M. P.; Zhao, Y.; Pan, D.; Manger, L. H.; Wright, J. C.; Goldsmith, R. H.; Jin, S. Chem. Mater. 2017, 29, 8385.

[81] Wang, Q.; Zheng, X.; Deng, Y.; Zhao, J.; Chen, Z.; Huang, J. Joule 2017, 1,1 .
[82] Wang, K.; Jin, Z.; Liang, L.; Bian, H.; Bai, D.; Wang, H.; Zhang, J.; Wang, Q.; Liu, S. Nat. Commun. 2018, 9, 4544.

[83] Xiang, S.; Li, W.; Wei, Y.; Liu, J.; Liu, H.; Zhu, L.; Chen, H. Nanoscale 2018, 10, 9996.

[84] Hu, Y.; Bai, F.; Liu, X.; Ji, Q.; Miao, X.; Qiu, T.; Zhang, S. ACS Energy Lett. 2017, 2, 2219.

[85] J ena, A. K.; Kulkarni, A.; Sanehira, Y.; Ikegami, M.; Miyasaka, T. Chem. Mater. 2018, 30, 6668.

[86] Nam, J. K.; Jung, M. S.; Chai, S. U.; Choi, Y. J.; Kim, D.; Park, J. H. J. Phys. Chem. Lett. 2017, 8, 2936.

[87] Fu, L.; Zhang, Y.; Li, B.; Zhou, S.; Zhang, L.; Yin, L. J. Mater Chem. A 2018, 6, 13263.

[88] Bai, D.; Zhang, J.; Jin, Z.; Bian, H.; Wang, K.; Wang, H.; Liang, L.; Wang, Q.; Liu, S. ACS Energy Lett. 2018, 3, 970.

[89] Beal, R. E.; Slotcavage, D. J.; Leijtens, T.; Bowring, A. R.; Belisle, R. A.; Nguyen, W. H.; Burkhard, G. F.; Hoke, E. T.; McGehee, M. D. J. Phys. Chem. Lett. 2016, 7, 746.

[90] Li, W.; Rothmann, M. U.; Liu, A.; Wang, Z. Y.; Zhang, Y. P.; Pascoe, A. R.; Lu, J. F.; Jiang, L. C.; Chen, Y.; Huang, F. Z.; Peng, Y.; Bao, Q. L.; Etheridge, J.; Bach, U.; Cheng, Y. B. Adv. Energy Mater. 2017, 7, 1700946

[91] Zeng, Z.; Zhang, J.; Gan, X.; Sun, H.; Shang, M.; Hou, D.; Lu, C.; Chen, R.; Zhu, Y.; Han, L. Adv. Energy Mater. 2018, 8, 1801050.

[92] Zeng, Q.; Zhang, X.; Feng, X.; Lu, S.; Chen, Z.; Yong, X.; Redfern, S. A. T.; Wei, H.; Wang, H.; Shen, H.; Zhang, W.; Zheng, W.; Zhang, H.; Tse, J. S.; Yang, B. Adv. Mater. 2018, 30, 1705393.

[93] Ma, Q. S.; Huang, S. J.; Wen, X. M.; Green, M. A.; Ho-Bailie, A. W. Y. Adv. Energy. Mater. 2016, 6, 1502202.

[94] Zhu, W.; Zhang. Q.; Chen, D.; Zhang, Z.; Lin, Z.; Chang, J. ; Zhang, J.; Zhang, C.; Hao, Y. Adv. Energy. Mater. 2018, 8, 1802080.

[95] Jiang, Y.; Yuan, J.; Ni, Y.; Yang, J.; Wang, Y.; Jiu, T.; Yuan, M.; Chen, J. Joule 2018, 2, 1356.

[96] MØLler, C. K. Nature 1958, 182, 1436.

[97] Kulbak, M.; Cahen, D.; Hodes, G. J. Phys. Chem. Lett. 2015, 6, 2452.

[98] Liang, J.; Wang, C.; Wang, Y.; Xu, Z.; Lu, Z.; Zhu, H.; Xiao, C.; Yi, X. J. Am. Chem. Soc. 2016, 138, 15829.

[99] Li, Y.; Wang, Y.; Zhang, T.; Yoriya, S.; Kumnorkaew, P.; Chen, S.; Guo, X.; Zhao, Y. Chem. Commun. 2018, 54, 9089.

[100] Bai, D. L.; Bian, H.; Jin, Z. W.; Wang, H. R.; Meng, L.; Wang, Q.; Liu, S. Z. Nano Energy 2018, 52, 408.

[101] Zhang, Q.; Zhu, W.; Chen, D.; Zhang, Z.; Lin, Z.; Chang, J.; Zhang, J.; Zhang, C.; Hao, Y. ACS Appl. Mater. Interfaces 2019, 11, 2997.

[102] Fu, Y. P.; Rea, M. T.; Chen, J.; Morrow, D. J.; Hautzinger, M. P.; Zhao, Y. Z.; Pan, D. X.; Manger, L. H.; Wright, J. C.; Goldsmith, R. H.; Jin, S. Chem. Mater. 2017, 29, 8385.

[103] Chen, Y. C.; Xiao, Y. Y.; Meng, Q.; Han, C. B.; Yan, H.; Zhang, Y. Z. Nano Energy 2020, 67, 104249.

(Cheng, F.) 